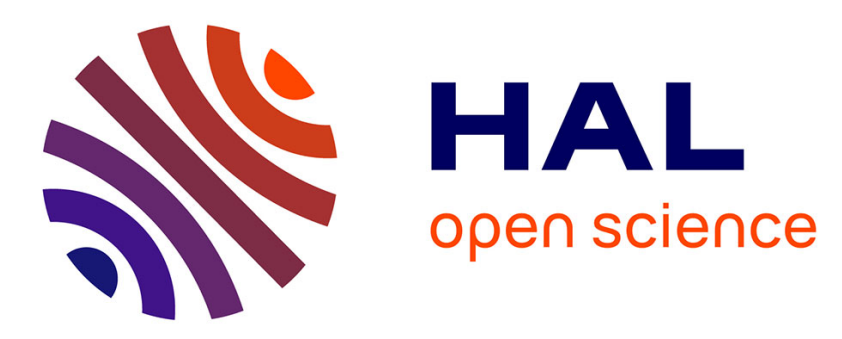

\title{
Autobiographical memory in semantic dementia: new insights from two patients using fMRI.
}

Armelle Viard, Béatrice Desgranges, Vanessa Matuszewski, Karine Lebreton, Serge Belliard, Vincent de La Sayette, Francis Eustache, Pascale Piolino

\section{To cite this version:}

Armelle Viard, Béatrice Desgranges, Vanessa Matuszewski, Karine Lebreton, Serge Belliard, et al.. Autobiographical memory in semantic dementia: new insights from two patients using fMRI.. Neuropsychologia, 2013, 51 (13), pp.2620-32. 10.1016/j.neuropsychologia.2013.08.007 . inserm-00864139

\section{HAL Id: inserm-00864139 https://www.hal.inserm.fr/inserm-00864139}

Submitted on 20 Sep 2013

HAL is a multi-disciplinary open access archive for the deposit and dissemination of scientific research documents, whether they are published or not. The documents may come from teaching and research institutions in France or abroad, or from public or private research centers.
L'archive ouverte pluridisciplinaire HAL, est destinée au dépôt et à la diffusion de documents scientifiques de niveau recherche, publiés ou non, émanant des établissements d'enseignement et de recherche français ou étrangers, des laboratoires publics ou privés. 
Viard et al.

\title{
Autobiographical memory in semantic dementia: new insights from two
}

\section{patients using fMRI}

\author{
Armelle Viard ${ }^{1,2,3,4^{*}}$, Béatrice Desgranges ${ }^{1,2,3,4}$, Vanessa Matuszewski ${ }^{1,2,3,4}$, Karine \\ Lebreton $^{1,2,3,4}$, Serge Belliard ${ }^{5}$, Vincent de La Sayette ${ }^{1,2,3,4}$, Francis Eustache ${ }^{1,2,3,4}$, \\ Pascale Piolino 6,7 \\ ${ }^{1}$ Inserm, U1077, Caen, France \\ ${ }^{2}$ Université de Caen Basse-Normandie, UMR-S1077, Caen, France \\ ${ }^{3}$ Ecole Pratique des Hautes Etudes, UMR-S1077, Caen, France \\ ${ }^{4}$ Centre Hospitalier Universitaire, U1077, Caen, France \\ ${ }^{5} \mathrm{CHU}$ Pontchaillou, Rennes, France \\ ${ }^{6}$ Université Paris Descartes, Institut de Psychologie, Memory and Cognition Lab, \\ Paris, France \\ ${ }^{7}$ Inserm UMR S894, Centre de Psychiatrie et Neurosciences, Paris, France
}

* Correspondance to : Inserm - EPHE - Université de Caen/Basse - Normandie, Unité U1077, GIP CYCERON, Bd Becquerel BP 5229, F-14074 Caen Cedex, France. Tel: +33(0)231065197, Fax: +33(0)231065198. E-mail address: viard@cyceron.fr (A. Viard)

Key words: autobiographical memory, semantic dementia, fMRI, hippocampus 
Viard et al.

\section{HIGHLIGHTS}

Using $\mathrm{fMRI}$, two SD patients retrieved recent and remote autobiographical memories

JPL presented severe hippocampal atrophy, while EP had preserved bilateral hippocampi

Episodic autobiographical retrieval was impaired in JPL, similar to controls for EP

JPL showed less left hippocampal activation, EP hyperactivated bilateral hippocampus

Both hyperactivated neocortical regions, inefficiently for JPL, efficiently for EP 
Viard et al.

\section{ABSTRACT}

Episodic autobiographical memory (EAM) consists of personal events embedded within a specific spatio-temporal context. Patients with semantic dementia (SD) generally show preserved recent EAMs, but a controversy remains concerning their ability to retrieve remote ones. Only one fMRI study examined remote autobiographical memory in SD through a longitudinal case study (Maguire et al., 2010). Here, we propose a cross-sectional study to test the hippocampo-neocortical up-regulation hypothesis, through a multimodal approach (gray matter volume, activation, connectivity analyses), directly comparing recent and remote autobiographical memory retrieval and collecting data to asses phenomelogical reexperiencing. EAM retrieval recruits a distributed network of brain regions, notably the hippocampus which is shown to be atrophied in SD, although some studies report no hippocampal atrophy in SD. Using fMRI, we examined recent and remote EAM retrieval in two SD patients with different profiles of hippocampal atrophy, compared to 12 healthy elders $(\mathrm{HE})$. JPL presented severe bilateral hippocampal atrophy, while EP showed sparing of both hippocampi. Behaviourally, JPL was impaired at retrieving EAMs from both life periods and showed poorer use of visual mental imagery than $\mathrm{HE}$, while EP retrieved memories which were as episodic as those of HE for both periods and relied on greater use of visual mental imagery than HE. Neuroimaging results showed that, for JPL, hyperactivations of the residual hippocampal tissue and of frontal, lateral temporal, occipital and parietal cortices did not efficiently compensate his autobiographical memory deficit. EP however presented hyperactivations in similar neocortical regions which appeared to be more efficient in compensating for atrophy elsewhere, since EP's EAM retrieval was preserved. Functional connectivity analyses focusing on the hippocampus showed how the residual hippocampal activity was connected to other brain areas. For JPL, 
Viard et al.

recent autobiographical retrieval was associated with connectivity between the posterior hippocampus and middle occipital gyrus, while for EP, connectivity was detected between the anterior hippocampus and numerous regions (medial temporal, occipital, temporal, frontal, parietal) for both recent and remote periods. These findings suggest that intensification of hippocampal atrophy in SD strongly affects both recent and remote autobiographical recollection. Up-regulation of neocortical regions and functional hippocampal-neocortical connectivity within the autobiographical network may be insufficient to compensate the lifelong episodic memory deficit for patients with extensive hippocampal atrophy. 
Viard et al.

\section{INTRODUCTION}

Semantic dementia (SD) is a variant of fronto-temporal dementia characterized by a gradual loss of semantic memory (Snowden et al., 1989), with progressive anomia and deterioration of vocabulary (Neary et al., 1998). An asymmetrical atrophy of the lateral temporal lobe is generally observed (Hodges and Patterson, 2007) with an antero-posterior gradient, the highest changes located in its anterior portion (Desgranges et al., 2007). A relative preservation of episodic memory is observed, with intact recent and day-to-day memory, while a controversy concerning the recall of remote autobiographical memories persists. Some studies report a reversed temporal gradient with preservation of recent relative to remote memories (Snowden et al., 1996; Graham and Hodges, 1997; Hodges and Graham, 1998; Graham et al., 1999, 2003; Nestor et al., 2002; Piolino et al., 2003a; Hou et al., 2005; Matuszewski et al., 2009). These patterns have been interpreted in favour of the standard theory of memory consolidation (Squire et al., 1997; McClelland et al., 1995; Murre et al., 1996; Bayley et al., 2005) which states that recent memories rely on the medial temporal lobe (MTL), while remote memories rely on neocortical regions, including the lateral temporal lobe. However, the standard theory does not distinguish between the two components (episodic and semantic) of declarative memory. Several studies on SD show impairments of the semantic aspects of autobiographical memory (e.g., names of acquaintances) which contrasts with relatively good recall of episodic autobiographical events (Piolino et al., 2003b; Duval et al., 2012). Some of these studies report a flat gradient showing a relative preservation of EAM across all life periods in SD (Westmacott et al., 2001; Moss et al., 2003; McKinnon et al., 2006; Maguire et al., 2010; Piolino et al., 2003b). These findings are consistent with the Multiple Trace Theory (MTT, Nadel and Moscovitch, 1997; Moscovitch et al., 2006) 
which argues in favour of a permanent involvement of the MTL, in particular the hippocampus, in the retrieval of EAMs, whatever their remoteness. One possible explanation for the conflicting findings might be the degree of hippocampal atrophy, a crucial structure involved in EAM retrieval (for review, Viard et al., 2012).

Evidence of hippocampal atrophy is now well documented in SD, even in the early stages of the disease (Chan et al., 2001; Good et al., 2002; Rosen et al., 2002; Boxer et al., 2003; Davies et al., 2004; van de Pol et al., 2006; Nestor et al., 2006; Desgranges et al., 2007; Lehmann et al., 2010; Acosta-Cabronero et al., 2011), although their remains a variability with some patients presenting no hippocampal atrophy (Mummery et al., 2000). Despite such hippocampal atrophy, SD patients are still able to retrieve autobiographical memories, at least to a greater extent than patients with Alzheimer's disease (AD; Hodges, 2012; Irish et al., 2011). Two observations can explain such discrepancies: a rostro-caudal gradient is observed in SD, with atrophy mainly localized in the anterior part of the hippocampus, while in patients with Alzheimer's disease, atrophy is located all along the axis of the hippocampus (Chan et al., 2001; Davies et al., 2004; for review, Hornberger and Piguet, 2012). Moreover, the limbic-diencephalic network (precuneus, posterior cingulate cortex), important in autobiographical memory (Maguire, 2001; Svoboda et al., 2006), is affected in AD (Hodges, 2012) which may explain their greater difficulty in retrieving autobiographical memories compared to SD (Nestor et al., 2006; Piolino et al., 2003a).

Studies on remote autobiographical memory in SD are scarce and only one fMRI study examined remote autobiographical memory in a patient suffering from SD (Maguire et al., 2010). In this longitudinal case study, the patient was examined on three separate occasions (years 1,2 and 3), with an episodic autobiographical recall 
task during fMRI scanning, followed by a debriefing session, performed each time. At year 1 , despite atrophy in the left hippocampus and left anterior temporal neocortex, the quality of the patient's recollection was similar to that of a single age-matched control subject and the "classic" autobiographical network (medial prefrontal and lateral temporal cortices, medial temporal lobe, medial parietal and retrosplenial cortices, occipital areas) was activated. Neuropsychological testing showed that he was impaired on a semantic fluency task and scored poorly on a verbal memory test (story recall), possibly reflecting his semantic and language difficulties. At year 2 , with atrophy starting to involve the contralateral areas (right hippocampus, right anterior temporal neocortex and right temporal pole, right cerebellum), his autobiographical memory gradually lost in specificity and recollective (i.e., episodic) quality and other neocortical areas were up-regulated (ventromedial and ventrolateral prefrontal cortices, right lateral temporal cortex and precuneus). Neuropsychological testing showed his naming difficulties became more pronounced and impairments in comprehension more evident. At year 3, there was significant atrophy of both temporal lobes, including both hippocampi (more extensive on the left) and right cerebellum, coinciding with a collapse of his autobiographical memory. Moreover, he became more withdrawn with increased word-finding difficulties, paraphasias and comprehension problems. By modelling the effects of memory remoteness parametrically, Maguire et al. (2010) found no changes in the brain network according to the age of memories, ranging from adolescence to the recent year. Memories from different life periods were however not directly compared to one another, rich re-experiencing via phenomenological scales was not probed and functional hippocampal-neocortical connectivity was not studied. 
Here, in the same vein as Maguire et al. (2010)'s pioneer study, we examined the effects of hippocampal atrophy on the integrity of the brain activity recorded by means of $\mathrm{fMRI}$ during EAM retrieval. We expected to confirm this previous work using a cross-sectional approach in a pathology which is scarcely studied with fMRI, not only to bring support to Maguire et al.'s (2010) findings, but also to confirm these results with a different paradigm and different patients. Moreover, we also expected to complement this previous work in a number of relevant ways, especially by adding further evidence regarding the hippocampal-neocortical regulation hypothesis in SD, via activation and connectivity analyses, and collecting numerous behavioural data to assess the degree of phenomenological re-experiencing (episodic quality, emotional intensity, valence, mental visual imagery, state of consciousness, repetition) in two SD patients with different profiles of atrophy: one had bilateral anterior hippocampal atrophy and the second had relatively preserved hippocampi. These patients were scanned while retrieving EAMs from two different life periods (recent and remote), ranging as far as childhood to the recent year. We examined whether or not a deficit in autobiographical memory recall in SD was present depending on the degree of atrophy and remoteness of memories. We recorded functional activations and performed connectivity analyses focusing on the hippocampus to show how the residual hippocampal activity was connected to other brain regions and if these connections had a compensatory effect in the two patients. Based on prior work in our laboratory (Viard et al., 2007, 2010; Piolino et al., 2004, 2008) in line with MTT, we predicted that hippocampal atrophy would affect recent and remote EAM retrieval, while a (relative) preservation of the hippocampus would permit EAM retrieval, whatever memory remoteness. Based on Maguire et al.'s (2010) prior fMRI study in $\mathrm{SD}$, we expected that, in the presence of atrophied regions within the 
autobiographical memory network, different processes might be observed: either activation in residual tissue, up-regulation of areas within the network or recruitment of additional brain areas. We expected that hippocampal atrophy would severely impair connectivity to other regions (e.g., neocortical) preventing rich autobiographical recollection, while intact hippocampi would continue to be functionally connected to the rest of the autobiographical network.

\section{MATERIALS AND METHODS}

\subsection{Participants}

\subsubsection{Patient details}

JPL, a 62-year-old right-handed male retired cutter with 10 years of formal education, was first seen in the CHU of Caen in November 2006. At that time, JPL reported progressive memory loss, particularly involving remembering peoples' names or familiar places and difficulty in word-finding. His wife reported a tendency to irritability, lack of initiative and poor conversational interactions. On formal neuropsychological testing, JPL showed relatively well preserved episodic memory (good free recall, but impaired immediate recall) as measured by a procedure derived from the Grober and Buschke test (Grober and Buschke, 1987; Eustache et al., 2001). Visuospatial abilities were good as measured by copying a complex figure (Rey, 1960). He scored poorly on semantic memory as measured by category (names of animals) and letter (words beginning by p) fluency tasks (Cardebat et al., 1990) and semantic knowledge task (Desgranges et al., 1996) specifically for picture naming and specific attributes of words. He performed poorly on the Mill Hill (French translation by Deltour 1993), a multiple-choice synonym vocabulary test which assesses verbal knowledge. His language abilities were tested with the LEXIS 
battery (de Partz et al., 2001). He produced numerous paraphasias (semantic and phonemic) and presented difficulties in picture naming, word-finding and word definitions.

EP, a 77-year-old right-handed female retired general practitioner with 20 years of formal education, was first seen in the $\mathrm{CHU}$ of Caen in April 2008. At that time, EP reported difficulties in word-finding and comprehension. She continued to have stimulating intellectual activities by attending university senior courses (to learn Latin and German) and reading intensely. On formal neuropsychological testing, EP showed relatively well preserved episodic memory as measured by a procedure derived from the Grober and Buschke test (Grober and Buschke, 1987; Eustache et al., 2001). Visuospatial abilities were good as measured by copying a complex figure (Rey, 1960). Given her high level of education, she scored relatively poorly on semantic memory as measured by category fluency tasks (names of animals; Cardebat et al., 1990). She produced errors on picture naming and on specific attributes of words on the semantic knowledge task (Desgranges et al., 1996). Her language abilities, tested with the LEXIS battery (de Partz et al., 2001) confirmed her difficulties in picture naming. She produced a number of paraphasias (semantic, visual, visuo-semantic) and had difficulties in providing word definitions (many specific attributes were lost).

An indicator of disease severity was obtained with the Mini-Mental Status Exam (MMSE; Folstein et al. 1975; total score/30) which assesses both comprehension and expression abilities through 8 different questions. Global cognitive functioning was assessed via the Mattis dementia rating scale (Mattis 1976; total score/144), signs of depression were estimated with the Geriatric Depression Scale (or GDS; Yesavage et al. 1983; total score/30). Table 1 summarizes both patients' 
neuropsychological scores and z-scores according to normative data provided for each test.

It is pertinent to make a parallel between our patients and Maguire et al.'s (2010) patient, AM, who was scanned over three consecutive years. As observed in semantic dementia, the three patients have poor performances on semantic memory tasks (e.g., picture naming, word-picture matching, picture-to-picture matching) and impaired semantic fluency (categorical), partly explained by atrophy in the lateral temporal lobes for each patient. Concerning AM, while the quality of his recollection was relatively preserved the first year, it declined progressively over the next two years. When comparing AM's longitudinal performances, it appears that in his first year of screening, he is comparable (although not identical) to EP, while comparable to JPL in his third year of screening (and second year, in some instances). Indeed, JPL and AM for years 2 and 3 have poor performances on the autobiographical memory task (i.e., poor episodic ratings) and both present atrophy in the bilateral anterior hippocampi. Other commonalities between JPL and AM are their education level (10 and 9 years, respectively) and gender (both males). Conversely, EP and $\mathrm{AM}$ at year 1 both present good episodic recollection. EP and AM differ however on education level (20 and 9 years, respectively), vocabulary performances (EP is unimpaired) and gender (EP is a female).

\subsubsection{Healthy participants}

Twelve right-handed healthy participants (females, mean age \pm s.d. $=67.2 \pm 5.2$ years; ranging from 60 to 75 years old), mean years of education (11.42 \pm 2.81$)$, with no history of psychiatric or neurological disorder were recruited through a university, a retirement association or a newspaper advertisement. Participants had no 
abnormality on their $\mathrm{T}_{1}$-weighted high-resolution magnetic resonance imaging (MRI). They underwent a battery of neuropsychological tests to assess their cognitive abilities and all performed in the normal range (see Viard et al., 2007, for a full description). Each participant resided at home and all were active in cultural pursuits, continuing education or with responsibilities in diverse associations.

The study was approved by the Regional Ethics Committee and written informed consent was obtained from all participants prior to their participation in the study. The present data on healthy participants were obtained as part of a broader experiment exploring five past life periods in aged adults previously published (Viard et al., 2007, 2010). Here, we present new results concerning two SD patients and compare them to the group of healthy participants. Of note, this group is not perfectly matched to each patient because it was originally scanned for another experiment. This group of healthy elders can nonetheless serve, to a certain extent, as a comparison group to our two patients, given that disparities have been partly controlled for by adding covariates in statistical analyses (see below).

\subsection{Task and experimental design}

Autobiographical memories from 5 life periods (childhood, early adulthood, late adulthood, past 5 years, last 12 months) were obtained through an interview with a close family member a week before the scanning session. Before scanning, participants were familiarized with the task in a training phase outside of the scanner, using different events than in the experimental task. Special care was taken to explain to the patients the tasks they had to perform. Personal sentence-cues were presented visually in white on a black background, using Superlab software (3.0 version, Cedrus). Upon presentation of the visual cue, participants had to recall their 
autobiographical memory by pressing on a button as soon as they gained access to the prompted event. Each experimental block lasted 24 seconds: the sentence-cue was presented for 5 seconds, followed by a black screen presented for 19 seconds during which participants continued their mental retrieval. Each functional run, confined to one period and lasting 5 minutes, was composed of five experimental and five control blocks, randomly intermixed across subjects (for more details, see Viard et al., 2007). Given the profusion of results preventing a clear picture to emerge, we combined life periods into a recent period, encompassing the two recent periods (covering the last 5 years), and a remote period, encompassing the three remote periods (more than 5 years ago until childhood). In the control condition, participants were asked to detect the presence of two consecutive letters ("mb") in pseudo-words of six letters (for example, "speugr" or "mbieha") and were instructed to press on a button when "mb" was present in the pseudo-word. Five pseudowords were presented in each control block, each lasting 24 seconds ( 1 second for cue presentation, followed by 3.8 seconds for the response).

After scanning, participants retrieved all events again during a debriefing (mean duration of 2,5 hours) and rated them on behavioral scales. First, the episodic nature of the memories was rated by the investigators on a five-point scale taking into account the specificity of the content (single or repeated event), the spatiotemporal situation and the presence of details (perceptions, thoughts, feelings): 4 = specific event, situated in time and space, with sensory details; $3=$ specific event with few details, but situated in time and space; 2 = repeated or prolonged over time, situated in time and space; 1 = repeated or prolonged over time, not situated in time and space; 0 = absence of memory, or general information about a theme. Two independent experts (VM, PP), not blind to group membership, rated each memory. 
Of note, there was almost a complete agreement between the two raters. In rare cases of disagreement, the data were re-examined until a consensus was reached. This scale has been previously used in our lab (Piolino et al., 2004; Viard et al., 2007, 2010, 2011a), in particular with SD patients (Piolino et al., 2003a,b; Matuzsewski et al., 2009). Two autobiographical scores were obtained: the overall autobiographical score (AS; maximum score per period $4 \times 5=20$ ) which includes all the memories (specific and generic) and the strictly episodic score (ES) which takes into account the number of specific and detailed memories scoring 4 (maximum per period $4 \times 5=$ 20).

Second, in order to specify the different aspects of the recollective experience, participants were asked to rate their evocations on several analogical scales $(10-\mathrm{cm}$ lines; self-ratings) known to be crucial to control the degree of episodic reexperiencing (for more details see, Viard et al., 2007). These scales evaluated emotional intensity ( $0=$ no emotion to $10=$ very strong emotion), emotional valence $(0=$ very negative to $10=$ very positive $)$, mental strategy used $(0=$ verbal to $10=$ visual), mental image quality $(0=$ very blurry to $10=$ very clear $)$, number of mental images retrieved $(0=$ no images to $10=$ over than 10 images $)$, point of view $(0=$ observer; 1 = both; 2 = field $)$, state of consciousness $(0=$ know to $10=$ remember $)$, frequency of rehearsal ( $0=$ never to $10=$ very frequent) and recency of the last evocation $(0=$ today to $10=$ over 10 years ago $)$.

\subsection{MRI data acquisition}

A blocked functional MRI design was used. Lying in the scanner, participants viewed the display via a mirror to an active matrix video projector. Stimulus onset was synchronized with the acquisition of the first slice. Anatomical and functional 
MRIs were acquired on a General Electrics Signa 1.5 tesla MRI scanner (GE, BUC, France). First, a high-resolution T1-weighted MRI scan (T1-MRI) was acquired with a three-dimensional inversion recovery spoiled gradient echo sequence (matrix size = $256 \times 256 \times 128$; slice thickness = $1.5 \mathrm{~mm}$ ). Second, a proton density $/ \mathrm{T} 2$-weighted MRI scan (PD-MRI, T2-MRI) was acquired with 32 axial slices covering the entire brain and the superior part of the cerebellum (slice thickness $=3.8 \mathrm{~mm}$ ). Finally, functional images were acquired with echo planar imaging blood oxygen level dependent $(B O L D)$ sequence (repetition time $=6 \mathrm{~s}$, echo time $=60 \mathrm{~ms}$, flip angle $=$ $90^{\circ}$, matrix size $=64 \times 64 \times 32,50$ volumes, 3.8 -mm-thick slices) covering the same field of view as the T2-MRI acquisition.

\subsection{Construction of an old-adult template}

Using voxel-based morphometry (VBM5; Good et al., 2001), each individual T1MRIs of the healthy elders were segmented according to the unified segmentation procedure (Ashburner and Friston, 2005) with spatial normalization included. Mean templates were calculated based on the individual segmented and normalized T1MRIs, creating three separate old-adult templates according to tissue type (e.g. grey and white matters, cerebro-spinal fluid) which were then spatially smoothed using an 8-mm FWHM Gaussian kernel.

\subsection{Functional image pre-processing}

Functional images were processed and analyzed using the Statistical Parametric Mapping software (SPM5; Wellcome Department of Cognitive Neurology, London, United Kingdom; http://www.fil.ion.ucl.ac.uk/spml). The first six volumes of the functional acquisition were discarded, allowing for signal stabilization, and differences 
Viard et al.

in slice acquisition timing were corrected. Images were realigned to correct for interscan movement with the creation of resliced mean functional volumes (mean$\mathrm{fMRI}$ ). For inter-modalities registration, rigid registration matrices (mean-fMRI onto T2-MRI, PD-MRI onto T1-MRI, T1-MRI onto the old-adult template) were computed, combined and then applied to fMRI volumes. Individual T1-MRIs were then segmented using the old-adult templates as priors (obtained previously, one for each tissue type; see above) and normalized. In order to set the fMRI volumes into our oldadult space, functional $\mathrm{MRI}$ images were resampled using the normalization parameters obtained in the segmentation step. Finally, data were spatially smoothed with an 8-mm ${ }^{3}$ FWHM Gaussian kernel.

\subsection{Data analyses}

\subsubsection{Behavioral data analysis}

We used the simplest statistical test (Procock, 2006) to perform intra-group comparisons for each patient (for autobiographical scores). This test can be used to compare a score obtained by one individual in two different conditions (e.g., recent versus remote periods). This statistical test can also be used to directly compare JPL to EP. Z-scores were used for inter-group comparisons between each patient and healthy elders (HE) (for autobiographical scores and analogical scales). Results were considered significant at the standard z-score of $\pm 1.96, p<0.05$. To be able to make comparisons with other papers which tend to present data from more than two periods, z-scores for autobiographical ratings over the five periods are presented in Supplementary Materials (Table S1).

\subsubsection{VBM analyses}


In order to formally assess the extent of atrophy in both SD patients across the whole brain, we compared their structural MRI scans with those of the group of 12 healthy elders using voxel-based morphometry (VBM5; Ashburner \& Friston, 2005). Structural MRI images were analyzed using the optimised VBM procedure implemented in SPM5. Briefly, this involves a number of fully automated preprocessing steps including extraction of brain, spatial normalization into stereotactic $(\mathrm{MNI})$ space, segmentation into grey and white matter and CSF compartments, correction for volume changes induced by spatial normalization (modulation), and smoothing with a $12 \mathrm{~mm}$ full width at half maximum (FWHM) isotropic Gaussian kernel. The preprocessing procedures used in SPM5 have been shown to produce good results when matching brains with lesions to standardised templates (Crinion et al., 2007). Analyses focussed on grey matter. Each patient's structural scan was compared to healthy elders scans using a two sample t-test to investigate differences in grey matter volume. The significance level was set at $p<$ 0.05 FWE corrected for multiple comparisons (see Table S2 in Supplementary Materials).

To confirm results from the VBM procedure regarding the presence or absence of hippocampal atrophy, the bilateral hippocampi were delineated by the same rater (AV) using the Anatomist software (http://brainvisa.info) on the contiguous coronal slices of the native space T1-MRI of each participant, using a mouse-driven cursor on each slice, from anterior to posterior, relying on previously-published guidelines (Pruessner et al., 2000; Pantel et al., 2000). Resultant raw volumetric measures were normalized to the total intracranial volume obtained using the VBM procedure to compensate for inter-individual variability in head size. Z-scores were then used for inter-group comparisons of hippocampal volumes between each patient and the 
healthy elders. Results were considered significant at the standard z-score of \pm 1.96 , $\mathrm{p}<0.05$.

\subsection{3. $\mathrm{fMRI}$ data analyses}

A fixed-effect (within-subject) model was applied to the time-series of each participant. After filtering (high-pass filter: $96 \mathrm{~s}$ ), t-statistic maps were generated for (1) the contrasts period minus control task for each period ("P minus C") generating five contrasts, (2) the comparisons between the recent and remote periods and the corresponding control task generating two contrasts (remote minus control, recent minus control) and (3) direct comparisons between periods (see below). A conjunction analysis was performed over the five "P minus C" contrasts to detect cerebral regions activated in common by all periods. Time-series data from the three remote periods were concatenated and treated as the remote period (HE: mean \pm s.d.: $40,8 \pm 15,1$ years; JPL: $37,7 \pm 17,5$ years; EP: $49,5 \pm 21,0$ years). Time-series data from the two recent periods were concatenated and treated as the recent period (HE: 2,1 $\pm 1,8$ years; JPL: 2,0 $\pm 2,1$ years; EP: 2,0 $\pm 2,1$ years). T-statistic maps were generated for the four following contrasts: "recent period minus control task", "remote period minus control task", "[(recent period minus control task) minus (remote period minus control) task]" and the reverse for each participant. The second-level random effects analysis was conducted over contrast images obtained previously, applying the two sample t-test model of SPM5. To control for the age difference between patients and healthy elders, age was included as covariate. To control for difference in education level between EP and HE, education level was also included as covariate. Inter-group subtraction analyses were computed to determine which regions were differentially activated by patients and healthy elders when comparing 
Viard et al.

recent and remote periods. We report activations at a corrected FWE statistical threshold of $p<0.05$, cluster-level $k>10$ voxels. Coordinates of brain regions are reported in the $\mathrm{MNI}$ space.

\subsubsection{Psychophysiological interactions}

We explored for each patient how functional connectivity between each of the hippocampal peaks (revealed by the contrasts described above in "fMRI data analyses") and the rest of the brain changed as a function of recent and remote autobiographical memory retrieval using the psychophysiological interaction (PPI) method (Friston et al., 1997). The seed regions were the hippocampal peaks that were hyperactivated by each patient in the previous group analyses (for JPL, one hippocampal seed coordinate; for EP, five hippocampal seed coordinates). For the recent period compared to the control task, the coordinates of the centre of the seeds used for the PPI analyses were, for JPL, in the right hippocampus [40 -36 -8] and, for $E P$, in the right [20 -12 -14] and left [-32 -18 -10] and [-26 -12 -16] hippocampi. For the remote period compared to the control task, the coordinates of the seeds' centre were, for EP, in the right [24 -10 -14] and left [-28 -14 -16] hippocampi. Note that for JPL, since there was no hippocampal hyperactivation compared to healthy elders for the remote period compared to the control task, no PPI analyses could be performed for this period.

For each subject and for each seed, the neuronal activity for the contrast "(recent or remote) period minus control task" was extracted from a volume of interest (VOI; 6 $\mathrm{mm}$ radius sphere) centred on sphere centre coordinates detailed above. Then, a linear model was built for each subject using three regressors: (1) the psychological regressor represented memory retrieval (remote or recent) versus control task; (2) 
Viard et al.

the physiological regressor corresponded to the mean time course in each hippocampal VOI; (3) the psychophysiological regressor represented the interaction of interest between the psychological and physiological regressors. PPI results were reported at an uncorrected statistical threshold of $p<0.001$, cluster-level $k>10$ voxels. Coordinates of brain regions are reported in the MNI space.

\section{RESULTS}

\subsection{Behavioural results}

Autobiographical scores (AS and ES) did not show significant differences over the two life periods for JPL (simplest test: AS: $z=-0.27, p=0.394$; $E S: z=0.08, p=0.468$ ) and EP (simplest test: AS: $z=-0.04, p=0.484 ; E S: z=-0.21, p=0.417$ ). Inter-group comparisons showed significantly higher AS scores for both life periods and higher ES scores for the recent period for healthy elders (HE) compared to JPL (see Table 2). Conversely, no significant differences were observed for EP compared to HE on either autobiographical score (AS and ES), indicating that the episodic nature of memories for EP did not significantly differ from those of HE. Note that both patients were able to retrieve the memories prompted, although as indicated by autobiographical scores, memories retrieved by JPL were not as episodic as those of HE.

Analogical ratings of emotion showed significantly higher scores for both patients compared to HE (see Table 2). JPL and EP rated their recent memories with greater intensity at retrieval compared to HE. Concerning ratings of visual mental imagery, both patients differed with higher scores for HE compared to JPL on the number of images retrieved for recent memories and the use of a field perspective for remote memories. The opposite pattern is observed for EP who showed higher scores 
compared to $\mathrm{HE}$ on the number of images retrieved for recent (trend) and remote (trend) periods (see Table 2). When comparing directly both patients with the simplest statistical test (Procock, 2006), results showed that JPL retrieved significantly less mental images than EP for both recent $(p=0.026)$ and remote periods $(p=0.04)$.

\subsection{VBM results}

Results depicted on Figure 1 reveal areas of grey matter volume loss in JPL and EP compared to HE. For JPL, atrophy was primarily located in the bilateral hippocampus, middle and inferior temporal gyri, left superior temporal gyrus, bilateral superior, middle, inferior and medial frontal gyri, bilateral anterior and right middle cingulate cortices, and left middle occipital gyrus, (for full details of results, see Table S2 in Supplementary Materials). Quantitative measures of hippocampal volume confirmed a significant atrophy of the right $(z=-3.00)$ and left $(z=-3.13)$ hippocampi in JPL compared to HE (see Figure S1 in Supplementary Materials). Areas of grey matter volume loss in EP compared to HE are primarily centred in bilateral superior, middle, right inferior and left medial frontal gyri, bilateral parahippocampal gyri, left middle and right superior temporal gyri, bilateral superior, inferior parietal gyri and precuneus (see Table S3 in Supplementary Materials). EP showed relative preservation of both hippocampi. Quantitative measures of hippocampal volume confirmed that the right $(z=-1.47)$ and left $(z=-1.18)$ hippocampal volumes for EP were not significantly different from HE (see Figure S1).

\section{3. fMRI results}

3.3.1. JPL 
The conjunction analysis showed common activations between all life periods in the left superior frontal gyrus, bilateral precuneus, left middle temporal gyrus and occipital regions (left calcarine sulcis and bilateral lingual gyrus; see Table S4 in Supplementary Materials).

Compared to the control task, the remote period showed greater activations for JPL than HE mainly in the left inferior frontal gyrus, left inferior temporal gyus and left cuneus. JPL showed less activation than HE in the left anterior hippocampus (subthreshold at $p<0.001$, Table 3, Figure 2).

Compared to the control task, the recent period showed greater activations for JPL mainly in frontal (right superior and left inferior gyri) and occipital (right superior gyrus, left cuneus) regions and right posterior hippocampus compared to HE (Table 3, Figure 2).

Compared to the recent period, the remote period showed greater activations for JPL in the left inferior frontal gyrus compared to HE. Conversely, the recent period showed greater activations in the left middle frontal gyrus, compared to the remote period for JPL compared to HE (Table 5, Figure 3).

\subsection{2. $\mathrm{EP}$}

The conjunction analysis showed common activations between all life periods in frontal (left inferior, middle, superior and precentral gyri), temporal (right inferior gyrus), occipital (left middle, inferior and right lingual gyri) regions and the left anterior hippocampus (see Table S4 in Supplementary Materials). Hence, EP showed activations in similar regions as HE (hippocampus, superior and middle frontal gyri, angular and middle occipital gyri). 
Compared to the control task, the remote period showed greater activations for EP mainly in frontal (left middle and inferior gyri), parietal (left precuneus) and bilateral middle occipital gyri and bilateral anterior hippocampus compared to $\mathrm{HE}$ (Table 4, Figure 2). EP showed less activation than HE in the anterior cingulate cortex for the same contrast (see Table S5 in Supplementary Materials).

Compared to the control task, the recent period showed greater activations for EP in temporal (right superior gyrus), parietal (left superior gyrus) and occipital (left middle gyrus) regions and bilateral anterior hippocampus compared to HE (Table 4, Figure 2). EP showed less activation than HE mainly in frontal (left superior, right superior medial and middle gyri) and temporal (right superior, middle and inferior gyri) regions, and the right posterior hippocampus for the same contrast (see Table S5 in Supplementary Materials).

Compared to the recent period, the remote period showed greater activations for EP mainly in frontal (left superior and middle gyri), temporal (right superior gyrus) and parietal (left precuneus, left inferior gyrus) regions compared to HE. Conversely, the recent period showed greater activations in frontal regions (left middle and precentral gyri) compared to the remote period for EP compared to HE (Table 6, Figure 3).

\subsection{PPI results}

For JPL, compared to the control task, recent autobiographical retrieval was associated with greater functional connectivity between the right posterior hippocampus and the left middle occipital gyrus (see Table 7). For EP, compared to the control task, recent autobiographical retrieval was associated with greater functional connectivity between (1) the left anterior hippocampus and the right anterior and left posterior hippocampi, left fusiform gyrus and occipital regions 
(superior and inferior occipital and lingual gyri); (2) the left anterior hippocampus and the right anterior and left posterior hippocampi. Compared to the control task, remote autobiographical retrieval was associated with greater functional connectivity in EP between (1) the left anterior hippocampus and right superior temporal and left inferior frontal gyri; (2) the right anterior hippocampus and the right posterior hippocampus, as well as frontal (left inferior, bilateral middle and left superior medial gyri), temporal (right middle, inferior and superior gyri), parietal (right angular gyrus) and occipital (right cuneus) regions (see Table 7).

\section{DISCUSSION}

This study is one of the only two fMRI studies in SD (see also Maguire et al., 2010) and, to our knowledge, the first to investigate autobiographical memory-related fMRI activity and hippocampal-neocortical connectivity across two life periods in two SD patients with contrasting profiles of hippocampal atrophy. While Maguire et al. (2010) reports the case of a single patient in a longitudinal study, further confirming data were required. In this way, we examined two patients, one with strong bilateral hippocampal atrophy (JPL) and one with relatively spared hippocampal tissue (EP), both presenting lateral temporal atrophy. Behaviourally, autobiographical memories retrieved by JPL were significantly less episodic than healthy elders for both recent and remote periods, which contrasted with EP who retrieved events that were episodic for both life periods. When examining the EAM neural network, JPL showed less activation than healthy elders in the left anterior hippocampus when retrieving remote memories, while EP hyperactivated this region bilaterally for both recent and remote periods. Conversely, JPL showed hyperactivation of the right posterior hippocampus for the recent period, while this region was less active for EP. 
Furthermore, both patients showed atrophy in neocortical regions of the EAM network (lateral temporal and prefrontal cortices and occipital or parietal cortices). Despite significant volume loss, other neocortical regions were hyperactivated by each patient, the compensatory benefit being more efficient for EP than JPL whose autobiographical memory deficit was more pronounced. We first consider the nature of autobiographical recollection in both patients, and then consider their neural basis.

\subsection{Behavioral results and VBM analyses}

For both patients, autobiographical scores (AS and ES) were not significantly different between recent and remote periods, although preserved in EP, while impaired in JPL. JPL produced significantly less specific and detailed events than healthy elders for both periods. EP, however, retrieved events that were as episodic as those of healthy elders. Earlier studies in SD reported a reversed temporal gradient, with better recall of recent events compared to the more remote past (Snowden et al., 1996; Graham and Hodges, 1997; Hodges and Graham, 1998; Graham et al., 1999; Nestor et al., 2002; Piolino et al., 2003a; Hou et al., 2005). Irish et al. (2011) confirmed the reversed temporal gradient, but showed that for the recent period, SD patients nonetheless display compromised retrieval of specific contextual details (spatiotemporal and emotional) with preservation of others (event and perceptual). A number of studies did not find a reversed temporal gradient in SD, but instead, relatively preserved EAM across all life periods (Westmacott et al., 2001; Moss et al., 2003; Piolino et al., 2003b; McKinnon et al., 2006; Maguire et al., 2010) or a global deficit at a more severe stage of disease severity (Matuszewski et al., 2009). Our findings for both patients confirm these latter studies: while no differences are observed between both periods for both patients, profiles are actually opposed 
with JPL significantly impaired at retrieving episodic events, while EP is able to retrieve episodic events from both recent and remote periods. EP's good episodic recollection can be paralleled to Maguire et al.'s (2010) patient AM at year 1 of his screening, while JPL's poor episodic ratings on the autobiographical memory task is similar to patient AM's performances at years 2 and 3 which declined compared to the first year. Both JPL and AM at years 2 and 3 present atrophy in the bilateral anterior hippocampi.

Episodic autobiographical retrieval was further assessed through self-evaluations (or self-ratings) of emotion and visual mental imagery, central to the phenomenology of autobiographical recollection. Self-ratings of emotion show similar profiles in both patients, with greater intensity at retrieval of recent and remote autobiographical memories. Emotion is an important phenomenological characteristic of vivid and persistent autobiographical memories (Brewer, 1988; Berntsen and Rubin, 2002). Most behavioural studies in SD point to a disruption of emotional processing (for review, see Kumfor and Piguet, 2012), but experimental designs are generally based on recognition of non-personal stimuli (e.g., facial expressions, Rosen et al., 2002). Irish et al. (2011) found impaired emotion processing in a group of SD patients during an autobiographical recall task and suspected that atrophy in the amygdala, generally reported in such patients, might explain their disrupted emotional autobiographical memory recall. In our study, the amygdala was not found to be significantly atrophied in either patient which may explain the high scores our patients obtained on the emotional scale of intensity. An early report by Snowden et al. (2001) also indicated that SD patients showed "exaggerated reactions to sensory stimuli".

Self-ratings of visual mental imagery show interestingly that JPL and EP present opposite profiles. Ratings of JPL are lower than healthy elders for both life periods, 
Viard et al.

while, ratings of EP are higher than healthy elders for both recent and remote periods. When comparing directly both patients, results showed that JPL retrieved significantly less mental images than EP for both recent and remote periods. Vivid visual mental imagery increases the retrieval of EAMs and detailed memories are often accompanied by strong imagery reports (Brewer, 1988, 1996; Dewhurst and Conway, 1994; Greenberg and Rubin, 2003). Thus, EP retrieves events that are episodic in part due to rich visual mental imagery, while JPL is unable to rely on intact visual mental imagery probably due to his massive hippocampal atrophy, explaining his difficulty in retrieving episodic events. JPL's poor mental imagery could also be a by-product of his poor memory: his difficulty to retrieve episodic memories may explain why he retrieves fewer mental images.

These behavioural findings are consistent with the atrophic profiles of each patient, especially within the hippocampus. JPL presents major left anterior (and right posterior) hippocampal atrophy, as previously reported in SD patients (Chan et al., 2001; Davies et al., 2004). EP however shows preserved hippocampi, confirmed by quantitative measures of hippocampal volume, although atrophy in the adjacent parahippocampal gyrus is present bilaterally. Given the major role played by the hippocampus in EAM retrieval, it can explain JPL's difficulty in retrieving EAMs. Conversely, EP's preserved autobiographical memory is most likely due to sparing of both hippocampi, although a number of other regions (e.g., neocortical) are also necessary for EAM retrieval (see below).

\subsection{Activation results}

The profile of activation for each patient within the hippocampus was different: EP hyperactivated the anterior hippocampus bilaterally (for both periods compared to the 
control task), while JPL hyperactivated the right posterior hippocampus (for the recent period compared to the control task). Both patients however showed hyperactivations in similar neocortical regions (lateral frontal, lateral temporal and occipital cortices).

\subsubsection{Hippocampus}

The hippocampus is a core region of the EAM retrieval network (for reviews, Maguire, 2001; Svoboda et al., 2006). The conjunction analysis revealed that this region was commonly active when retrieving memories for all life periods in EP, but not JPL. Like EP, Maguire et al.'s (2010) patient AM at year 1 of his screening also activated the classic EAM network, including the left hippocampus, while at year 3 , mainly posterior regions (fusiform and occipital cortices) similar to JPL, were activated. Further analyses showed that each patient actually presented a different profile of activation according to its antero-posterior axis. The left anterior hippocampus was less activated in JPL compared to healthy elders for remote memories. This may be explained by JPL's left hippocampal atrophy which was more pronounced in its anterior portion. Conversely, EP hyperactivated the bilateral anterior hippocampus for both life periods and connectivity analyses showed that the left and right anterior hippocampi were functionally connected during (recent) autobiographical retrieval. Anterior hippocampal activation was also detected in Maguire et al.'s (2010) SD patient when his autobiographical recollection was still preserved (i.e., at year 1 of screening). We previously showed that both portions of the hippocampus are involved in autobiographical recollection, although more importantly in its anterior part (Viard et al., 2007). As shown in a recent metaanalysis, the use of personal cues is more likely to engage the anterior part of the 
hippocampus (Viard et al., 2012), as it is the case in this study (personal sentence cues) and in Maguire et al. (2010) where personal photos were used. Rajah et al. (2010) also showed that the anterior, but not posterior hippocampus, is more important for context memory retrieval. Hence, hyperactivation of the anterior hippocampus bilaterally may explain why EP, but not JPL, is able to retrieve EAMs for both life periods. These results confirm our predictions, based on MTT (Nadel and Moscovitch, 1997) and Maguire et al.'s (2010) findings, that hippocampal atrophy affects EAM retrieval, while intact hippocampi preserve EAM retrieval whatever memory remoteness.

Most interestingly, connectivity analyses in EP showed that the anterior hippocampus for both recent and remote periods was functionally connected to the ipsilateral posterior hippocampus. Due to different anatomical connections with other brains areas, the anterior and posterior hippocampi have distinct roles. The anterior hippocampus, closely connected to medial prefrontal areas and the amygdala, is associated with arousal, emotion and reward (Ferbinteanu and McDonald, 2001; Fanselow and Dong, 2010; Royer et al., 2010; for reviews, Moser and Moser, 1998; Ranganath and Ritchey, 2012) and their effects on memory (Wittmann et al., 2005; Adcock et al., 2006; Viard et al., 2011b). The posterior hippocampus, connected to visuo-spatial areas (retrosplenial and cingulate cortices, precuneus), is implicated in memory for spatial relations and preferentially involved in spatial memory (Hoscheidt et al., 2010). The interaction between both parts of the hippocampus may have contributed to EP's preserved episodic recollection by permitting the retrieval of both spatial and other contextual components of events. Conversely, JPL hyperactivated the (right) posterior hippocampus for the recent period, but not the anterior hippocampus. Functional connectivity analyses showed that the residual right 
Viard et al.

posterior hippocampal tissue was not connected to other portions of the hippocampus. Hence, the absence of anterior hippocampal activity and connectivity between the anterior and posterior parts of the hippocampus may play a part in explaining why JPL is unable to retrieve EAMs. Yet, his right posterior hippocampus is still functionally connected to a neocortical region (occipital) which may reflect a compensatory mechanism of the residual hippocampal tissue, although this compensation is not effective since behaviourally JPL retrieved less episodic events than healthy elders.

\subsubsection{Neocortical regions}

A number of neocortical regions were up-regulated within the autobiographical memory network for both patients, essentially in lateral temporal, occipital and frontal cortices. Hyperactivation of the lateral temporal cortex was detected for JPL (remote period) and EP (both periods) and connectivity results in EP showed that the bilateral anterior hippocampi were functionally connected to the lateral temporal cortex, a region known for its role in semantic autobiographical memory (Svoboda et al., 2006; Martinelli et al., 2013) and construction of EAMs (Conway, 2001; Viard et al., 2007). For JPL, this result is confirmed by behavioural ratings which indicate that memories were significantly less episodic (i.e. more semanticized) than healthy elders. Maguire et al. (2010) suggested that increased activation in the lateral temporal cortex in their SD patient, especially at year 2 of his screening, may reflect a decline in his semantic memory with increasing effort required to process the semantic content of the stimuli. For patients JPL and EP, atrophy is observed in the lateral temporal cortex suggesting that hyperactivation of the residual tissue may serve to compensate this atrophy. Piolino et al. (2003b) also reported the case of a SD patient with temporal 
neocortical atrophy, with good recall of autobiographical events from all life periods, but poor retrieval of names of acquaintances. The conjunction analyses over all life periods revealed lateral temporal activity in JPL and EP, as well as in Maguire et al.'s (2010) patient at years 1 and 2 of his screening. These results suggest that significant volume loss in key regions of the autobiographical memory network does not imply that the residual tissue is not active, as noted by Maguire et al. (2010), although the efficiency of such regions appears dependent on intact bilateral hippocampi. Indeed, although the three patients present lateral temporal hyperactivation, only EP and Maguire et al.'s (2010) patient at year 1 show preserved EAM retrieval and relatively preserved hippocampi, while JPL and Maguire's patient at years 2 and 3 present poor episodic recollection and bilateral hippocampal atrophy.

Posterior hyperactivations in the occipital cortex were also observed in both patients and also hyperactivated in Maguire et al.'s (2010) patient over the three years of his screenings. This region is known for visual processing which in our task is most likely to reflect visual mental imagery. Yet, JPL showed lower scores on visual mental imagery than healthy elders (recent period), while hyperactivation was present in the right occipital cortex and atrophy was detected in the left occipital cortex. Right hyperactivation may reflect a compensatory mechanism for atrophy present in the contralateral area, although it appears not sufficient for JPL to rely efficiently on visual mental imagery. Similarly, Maguire et al.'s (2010) patient at year 3 showed occipital hyperactivations, although the quality if his autobiographical recollection was severely impaired. The residual posterior hippocampal tissue in JPL was functionally connected to a preserved area of the left occipital cortex, suggesting that the occipital involvement during autobiographical retrieval in JPL may have had 
Viard et al.

a compensatory role. EP also exhibits hyperactivations in the occipital cortex bilaterally for both life periods which, unlike JPL, are coherent with her behavioural ratings of visual mental imagery.

Unlike Maguire et al. (2010) who found no changes in response to the age of memory in their SD patient (ranging from adolescence to the past year), when comparing directly remote (from birth to last 5 years) and recent (last 5 years including the 12 last months) periods, hyperactivations in lateral frontal regions were detected in both patients: inferior frontal (or ventrolateral prefrontal) cortex for remote compared to recent periods and middle frontal (or dorsolateral prefrontal) cortex for recent compared to remote periods. The inferior frontal cortex has a role in cue specification and controlled retrieval of information from posterior associative regions (Cabeza and St Jacques, 2007) and in maintaining search results online (Svoboda et al., 2006). Thus, remote memories appear to rely on more cue specification and controlled retrieval strategies than recent memories, possibly to maintain search results online. The middle frontal cortex has a role in monitoring processes (Svododa et al., 2006) and manipulating the products of retrieval in working memory (Cabeza and St Jacques, 2007). The recent period was composed of more mundane events of everyday life that happened more recently, unlike remote memories which were probably more self-defining, in particular those of early adulthood (e.g., from the reminiscence bump, see above). Hence, retrieving recent memories may have relied more on monitoring processes than remote memories which were more readily accessible (Gilboa et al., 2004).

\subsection{Limits and conclusion}


Albeit the clinical and theoretical relevance of the present findings, some potential limits should be mentioned. The group of healthy elders used for comparison is not perfectly matched to each patient, since, as mentioned above, this group was originally scanned for another experiment. Hence, a potential bias of the present study is that a male (JPL) was compared to a female patient (EP) and a group of healthy females. Semantic dementia affects similarly males and females (Belliard et al., 2007; Thomson et al., 2003) and no studies have shown a gender effect in this pathology. However, some studies have demonstrated gender differences favouring women on episodic-memory tasks requiring verbal processing, but favouring men when requiring visuospatial processing (Herlitz et al., 1997; St Jacques et al., 2011; Andreano and Cahill, 2009). In this context, the gender difference between JPL and EP may not explain their differences, and the gender difference between JPL and the control group could play only a marginal role in the present results as mental retrieval of autobiographical memory involves both verbal and visuospatial processing. Neuroimaging studies investigating gender effects on the autobiographical memory retrieval (Piefke et al., 2005; St Jacques et al., 2011) showed that males and females recruit a common network (e.g., anterior hippocampus, lateral temporal and prefrontal regions), similar to regions reported here. Yet, males activated more the left parahippocampal gyrus (Piefke et al., 2005) and less the left inferior frontal gyrus and posterior hippocampus than females (St Jacques et al., 2011), while females showed greater activation in the right middle frontal gyrus than males. These results suggest that males relied more on medial temporal regions associated with visuospatial processing, while females relied more on prefrontal regions linked to controlled processes (e.g., temporal context). Here, these regions either did not appear in the comparisons between JPL and healthy elders or the opposite pattern 
was observed. Similarly, Maguire et al.'s (2010) male SD patient did not activate the inferior frontal gyrus and posterior hippocampus during autobiographical recall. Although it is obviously difficult to conclude from single-case analyses, our results do not seem to reflect gender differences between JPL and healthy elders, but rather the genuine up-regulation of a neural network, in an attempt to retrieve EAMs in spite of severe brain atrophy.

Another possible critic resides in the higher education level of EP (20 years) compared to JPL (10 years) which may have played a role in EP's preserved autobiographical memory (Angel et al., 2010). A number of studies show that elders with higher cognitive reserve (e.g., education level, IQ) exhibit reduced brain activity, reflecting a more effective use of cerebral networks (Solé-Padullés et al., 2009; Bosch et al., 2010; Stern et al., 2002). Yet, Maguire et al.'s (2010) patient in his first year of screening, with an education level of 9 years, presented a similar profile to EP (preserved episodic recollection, activation of the classic autobiographical memory network). Furthermore, we attempted to control for this difference by adding EP's education level as a covariate in all analyses to control for parametric variations in education level between subjects. JPL's education level did not differ from controls' education level (11.42 years) suggesting that his hippocampal and neocortical atrophy is largely responsible of his autobiographical memory deficit.

Finally, there are age differences between the two patients and between each patient (particularly EP) and the group of healthy elders. The only way to compare EP to aged-matched controls would have been to include new subjects (impossible since the MRI scanner was no longer in use). Yet, by adding age as a covariate in all analyses, we hope to have attenuated the age confound between patients, in particular EP, and healthy elders. 
In summary, we examined autobiographical memory retrieval over two life periods in two SD patients with contrasting profiles of hippocampal atrophy. With bilateral hippocampal atrophy, JPL retrieved autobiographical memories that were less episodic than those of healthy elders regardless of remoteness and had a poorer use of visual mental imagery compared to healthy elders. Hyperactivations of the residual posterior hippocampal tissue and in various neocortical regions (lateral temporal, occipital and frontal cortices) do not appear to efficiently compensate JPL's autobiographical memory deficits, neither did the functional connectivity of the residual posterior hippocampal tissue. On the contrary, EP's hippocampi were preserved and hyperactivations were detected bilaterally for both life periods. EP was able to retrieve memories as episodic as those of healthy elders and relied on greater use of visual mental imagery than healthy elders. Hyperactivations in similar neocortical regions (lateral temporal, occipital and frontal cortices) as JPL were more efficient in compensating for atrophy elsewhere, since EP's episodic autobiographical retrieval was preserved. Functional connectivity between the bilateral anterior and posterior hippocampi and to numerous neocortical regions helped EP to fully reexperience in detail her autobiographical memories. Taken together, these findings suggest that intensification of hippocampal atrophy in SD strongly affects autobiographical recollection and up-regulation of neocortical regions and functional connectivity within the autobiographical network may be insufficient to compensate the memory deficit for patients with extensive hippocampal atrophy. We confirm here the key role of the hippocampus in episodic autobiographical recollection. Nevertheless, further studies should be performed to address properly the contribution of inter-individual factors such as gender, level of education and age. 
Viard et al.

Acknowledgements: This work was supported by the Fondation pour la Recherche sur le Cerveau (FRC). Thanks to Dr. Alan Young for his help scanning participants and to Robin de Florès and Renaud La Joie for advice concerning hippocampal tracing. 
Viard et al.

\section{References}

Adcock, R.A., Thangavel, A., Whitfield-Gabrieli, S., Knutson, B., Gabrieli, J.D. (2006). Reward-motivated learning: mesolimbic activation recedes memory formation. Neuron, 50, 507-517.

Acosta-Cabronero, J., Patterson, K., Fryer, T. D., Hodges, J. R., Pengas, G., Williams, G. B., \& Nestor, P. J. (2011). Atrophy, hypometabolism and white matter abnormalities in semantic dementia tell a coherent story. Brain, 134, 2025-2035.

Andreano, J.M., Cahill, L. (2009). Sex influences on the neurobiology of learning and memory. Learning and Memory, 24, 16, 248-266.

Angel, L., Fay, S., Bouazzaoui, B., Baudouin, A., Isingrini, M. (2010). Protective role of educational level on episodic memory aging: an event-related potential study. Brain and Cognition, 74, 312-323.

Ashburner, J., \& Friston, K. J. (2005 ). Unified segmentation. Neuroimage, 26, 839-851.

Belliard, S., Bon, L., LeMoal, S., Jonin, P.Y., Vercelletto, M., LeBail, B. (2007). Démence sémantique. Psychologie et NeuroPsychiatrie du Vieillissement, 5, 127138.

Berntsen, D., \& Rubin, D. C. (2002). Emotionally charged autobiographical memories across the life span: the recall of happy, sad, traumatic, and involuntary memories. Psychology Aging, 17, 636-652.

Boxer, A. L., Rankin, K. P., Miller, B. L., Schuff, N., Weiner, M., Gorno-Tempini, M. L., \& Rosen, H. J. (2003). Cinguloparietal atrophy distinguishes Alzheimer disease from semantic dementia. Archives of Neurology, 60, 949-956.

Brewer, W. (1988). Memory for randomly sampled autobiographical events. In U. Neisser, E. Winograd (Eds.), Remembering reconsidered: ecological and traditional approaches to the study of memory (pp. 21-90). Cambridge: Cambridge University Press.

Brewer, W. (1996). What is recollective memory? In D.C. Rubin (Ed.), Remembering our past: studies in autobiographical memory (pp. 19-66). Cambridge: Cambridge University Press.

Cabeza, R., \& St Jacques, P. (2007). Functional neuroimaging of autobiographical memory. Trends in Cognitive Sciences, 11, 219-227.

Cardebat, D., Doyon, B., Puel, M., Goulet, P., \& Joanette, Y. (1990). [Formal and semantic lexical evocation in normal subjects. Performance and dynamics of 
production as a function of sex, age and educational level]. Acta neurologica belgica, 90, 207-217.

Chan, D., Fox, N. C., Scahill, R. I., Crum, W. R., Whitwell, J. L., Leschziner, G., Rossor. A. M., Stevens, J. M., Cipolotti, L., \& Rossor, M. N. (2001). Patterns of temporal lobe atrophy in semantic dementia and Alzheimer's disease. Annals of Neurology, 49, 433-442.

Conway, M. A. (2001). Sensory-perceptual episodic memory and its context: autobiographical memory. Philosophical Transaction of the Royal Society of London: Series $B, 356,1375-1384$.

Crinion, J., Ashburner, J., Leff, A., Brett, M., Price, C., \& Friston, K. (2007). Spatial normalization of lesioned brains: performance evaluation and impact on fMRI analyses. Neuroimage, 37, 866-875.

Davies, R. R., Graham, K. S., Xuereb, J. H., Williams, G. B., \& Hodges, J. R. (2004). The human perirhinal cortex and semantic memory. European Journal of Neuroscience, 20, 2441-2446.

de Partz, M. P., Bilocq, V., De Wilde, V., Seron, X. \& Pillon, A. (2001). LEXIS: Tests pour l'évaluation des troubles lexicaux chez la personne aphasique. Marseille: Solal.

Deltour, J.J. (1993). Echelle de vocabulaire de Mill Hill de JC Raven. Adaptation française et normes européennes du Mill Hill et du Standard Progressive Matrices de Raven. Braine-le-Chateau: Editions l'application des techniques modernes.

Desgranges, B., Eustache, F., Rioux, P., de La Sayette, V., \& Lechevalier, B. (1996). Memory disorders in Alzheimer's disease and the organization of human memory. Cortex, 32, 387-412.

Desgranges, B., Matuszewski, V., Piolino, P., Chételat, G., Mézenge, F., Landeau, B., de la Sayette, V., Belliard, S., \& Eustache, F. (2007). Anatomical and functional alterations in semantic dementia: a voxel-based MRI and PET study. Neurobiology of Aging, 28, 1904-1913.

Dewhurst, S. A., \& Conway, M. A. (1994). Pictures, images, and recollective experience. Journal of Experimental Psychology: Learning, Memory, and Cognition, 20, 10881098.

Duval, C., Desgranges, B., de La Sayette, V., Belliard, S., Eustache, F., Piolino, P. (2012). What happens to personal identity when semantic knowledge degrades? A study of the self and autobiographical memory in semantic dementia. 
Viard et al.

Neuropsychologia, 50, 254-265.

Eustache, F., Desgranges, B., De La Sayette, V., Lalevée, C., Giffard, B., Piolino, P., Viader, F., \& Baron, J. C. (2001). [Contribution of positron emission tomography to functional neuroimaging in Alzheimer's disease]. Revue Neurologique (Paris), 157, 377-383.

Fanselow, M.S., Dong, H.W. (2010). Are the dorsal and ventral hippocampus functionally distinct structures? Neuron, 65, 7-19.

Ferbinteanu, J., McDonald, R.J. (2001). Dorsal/ventral hippocampus, fornix, and conditioned place preference. Hippocampus, 11, 187-200.

Friston, K.J., Buechel, C., Fink, G.R., Morris, J., Rolls, E., \& Dolan, R.J. (1997). Psychophysiological and modulatory interactions in neuroimaging. Neuroimage, 6, 218-229.

Gilboa, A., Winocur, G., Grady, C. L., Hevenor, S. J., \& Moscovitch, M. (2004). Remembering our past: functional neuroanatomy of recollection of recent and very remote personal events. Cerebral Cortex, 14, 1214-1225.

Good, C. D., Johnsrude, I. S., Ashburner, J., Henson, R. N., Friston, K. J., \& Frackowiak, R. S. (2001). A voxel-based morphometric study of ageing in 465 normal adult human brains. Neuroimage, 14, 21-36.

Good, C. D., Scahill, R. I., Fox, N. C., Ashburner, J., Friston, K. J., Chan, D., Crum, W. R., Rossor, M. N., \& Frackowiak, R. S. (2002). Automatic differentiation of anatomical patterns in the human brain: validation with studies of degenerative dementias. Neuroimage, 17, 29-46.

Graham, K. S., \& Hodges, J. R. (1997). Differentiating the roles of the hippocampal complex and the neocortex in long-term memory storage: evidence from the study of semantic dementia and Alzheimer's disease. Neuropsychology, 11, 77-89.

Graham, K. S., Kropelnicki, A., Goldman, W. P., \& Hodges, J. R. (2003). Two further investigations of autobiographical memory in semantic dementia. Cortex, 39, 729750.

Graham, K. S., Patterson, K., \& Hodges, J. R. (1999). Episodic memory: new insights from the study of semantic dementia. Current Opinion in Neurobiology, 9, 245-250.

Greenberg, D. L., \& Rubin, D. C. (2003). The neuropsychology of autobiographical memory. Cortex, 39, 687-728

Grober, E., \& Buschke, H. (1987). Genuine memory deficits in dementia. Developmental 
Viard et al.

Neuropsychology, 3, 13-36.

Herlitz, A., Nilsson, L.G., Bäckman, L. (1997). Gender differences in episodic memory. Memory and Cognition, 25, 801-811.

Hodges, J. R., \& Graham, K. S. (1998). A reversal of the temporal gradient for famous person knowledge in semantic dementia: implications for the neural organisation of long-term memory. Neuropsychologia, 36, 803-825.

Hodges, J. R., \& Patterson, K. (2007). Semantic dementia: a unique clinicopathological syndrome. Lancet Neurology, 6(11):1004-14.

Hodges, J. R. (in press). Alzheimer's Disease and the Frontotemporal Dementias:

Contributions to Clinico-Pathological Studies, Diagnosis, and Cognitive Neuroscience. Journal of Alzheimer's Disease.

Hornberger, M., \& Piguet, O. (2012). Episodic memory in frontotemporal dementia: a critical review. Brain, 135, 678-692.

Hoscheidt, S. M., Nadel, L., Payne, J., \& Ryan, L. (2010). Hippocampal activation during retrieval of spatial context from episodic and semantic memory. Behavioural Brain Research, 212, 121-132.

Hou, C. E., Miller, B. L., \& Kramer, J. H. (2005). Patterns of autobiographical memory loss in dementia. International Journal of Geriatric Psychiatry, 20, 809-815.

Irish, M., Hornberger, M., Lah, S., Miller, L., Pengas, G., Nestor, P. J., Hodges, J. R., \& Piguet, O. (2011). Profiles of recent autobiographical memory retrieval in semantic dementia, behavioural-variant frontotemporal dementia, and Alzheimer's disease. Neuropsychologia, 49, 2694-2702.

Irish, M., Piguet, O. (2013). The pivotal role of semantic memory in remembering the past and imagining the future. Frontiers in Behavioral Neuroscience, 7, 27.

Kumfor, F., \& Piguet, O. (2012). Disturbance of emotion processing in frontotemporal dementia: a synthesis of cognitive and neuroimaging findings. Neuropsychological Reviews, 22, 280-297.

Lehmann, M., Douiri, A., Kim, L. G., Modat, M., Chan, D., Ourselin, S., Barnes, J., \& Fox, N. C. (2010). Atrophy patterns in Alzheimer's disease and semantic dementia: a comparison of FreeSurfer and manual volumetric measurements. Neuroimage, 49, 2264-2274.

Maguire, E. A. (2001). Neuroimaging studies of autobiographical event memory. Philosophical Transaction of the Royal Society of London: Series B, 356, 1441-1451. 
Bonnici, H. M., Chadwick, M. J., Lutti, A., Hassabis, D., Weiskopf, N., \& Maguire, E. A. (2012). Detecting representations of recent and remote autobiographical memories in vmPFC and hippocampus. Journal of Neuroscience, 32, 16982-16991.

Maguire, E. A., \& Frith, C. D. (2003). Lateral asymmetry in the hippocampal response to the remoteness of autobiographical memories. Journal of Neuroscience, 23, 53025307.

Maguire, E. A., Kumaran, D., Hassabis, D., \& Kopelman, M. D. (2010). Autobiographical memory in semantic dementia: a longitudinal fMRI study. Neuropsychologia, 48, 123-136.

Martinelli, P., Sperduti, M., \& Piolino, P. (in press). Neural substrates of the self-memory system: New insights from a meta-analysis. Human Brain Mapping.

Mattis, S. (1976). Mental status examination for organic mental symptoms in elderly patients. In: L. Bellak, T.B. Karatsu (Eds). Geriatric psychiatry: a handbook for psychiatrists and primary care physicians (p. 77-121). New York: Grune et Stratton.

Matuszewski, V., Piolino, P., Belliard, S., de la Sayette, V., Laisney, M., Lalevée, C., Pélerin, A., Viader, F., Eustache, F., \& Desgranges, B. (2009). Patterns of autobiographical memory impairment according to disease severity in semantic dementia. Cortex, 45, 456-472.

McKinnon, M. C., Black, S. E., Miller, B., Moscovitch, M., \& Levine, B. (2006). Autobiographical memory in semantic dementia: implication for theories of limbicneocortical interaction in remote memory. Neuropsychologia, 44, 2421-2429.

Moser, M.B., Moser, E.I. (1998). Functional differentiation in the hippocampus. Hippocampus, 8, 608-619.

Moss, H. E., Kopelman, M. D., Cappalletti, M., De Mornay Davies, P., \& Jaldow, E. (2003). Lost for words or loss of memories? Autobiographical memory in semantic dementia. Cognitive Neuropsychology, 20, 703-732.

Mummery, C.J., Patterson, K., Price, C.J., Ashburner, J., Frackowiak, R.S., Hodges, J.R. (2000). A voxel-based morphometry study of semantic dementia: relationship between temporal lobe atrophy and semantic memory. Annals of Neurology, 47, 3645.

Nadel, L., \& Moscovitch, M. (1997). Memory consolidation, retrograde amnesia and the hippocampal complex. Current Opinion in Neurobiology, 7, 217-227.

Neary, D., Snowden, J. S., Gustafson, L., Passant, U., Stuss, D., Black, S., Freedman, 
M., Kertesz, A., Robert, P. H., Albert, M. S., Boone, K., Miller, B. L., Cummings, J. L., \& Benson, D. F. (1998). Frontotemporal lobar degeneration: a consensus on clinical diagnostic criteria. Neurology, 51, 1546-1554.

Nestor, P. J., Graham, K. S., Bozeat, S., Simons, J. S., \& Hodges, J. R. (2002). Memory consolidation and the hippocampus: Further evidence from studies of autobiographical memory in semantic dementia and frontal variant frontotemporal dementia. Neuropsychologia, 40, 633-654.

Nestor, P. J., Fryer, T. D., \& Hodges, J. R. (2006). Declarative memory impairments in Alzheimer's disease and semantic dementia. Neuroimage, 30, 1010-1020.

Pantel, J., O'Leary, D.S., Cretsinger, K., Bockholt, H.J., Keefe, H., Magnotta, V.A., Andreasen, N.C. (2000). A new method for the in vivo volumetric measurement of the human hippocampus with high neuroanatomical accuracy. Hippocampus, 10, 752-758.

Piolino, P., Desgranges, B., Belliard, S., Matuszewski, V., Lalevée, C., De la Sayette, V., \& Eustache, F. (2003a). Autobiographical memory and autonoetic consciousness: triple dissociation in neurodegenerative diseases. Brain, 126, 22032219.

Piolino, P., Belliard, S., Desgranges, B., Perron, M., \& Eustache, F. (2003b). Autobiographical memory and autonoetic consciousness in a case of semantic dementia. Cognitive Neuropsychology, 20, 619-639.

Piolino, P., Giffard-Quillon, G., Desgranges, B., Chételat, G., Baron, J. C., \& Eustache, F. (2004). Re-experiencing old memories via hippocampus: a PET study of autobiographical memory. Neuroimage, 22, 1371-1383.

Piolino, P., Desgranges, B., Hubert, V., Bernard, F. A., Matuszewski, V., Chételat, G., Baron, J. C., \& Eustache, F. (2008). Reliving lifelong episodic autobiographical memories via the hippocampus: a correlative resting PET study in healthy middleaged subjects. Hippocampus, 18, 445-459.

Procock, S. (2006). The simplest statistical test : how to check for a difference between treatments. British Journal of Medicine, 332, 1256-1258.

Pruessner, J.C., Li, L.M., Serles, W., Pruessner, M., Collins, D.L., Kabani, N., Lupien, S., Evans, A.C. (2000). Volumetry of hippocampus and amygdala with highresolution $\mathrm{MRI}$ and three-dimensional analysis software: minimizing the discrepancies between laboratories. Cerebral Cortex, 10, 433-442. 
Rajah, M. N., Kromas, M., Han, J. E., \& Pruessner, J. C. (2010). Group differences in anterior hippocampal volume and in the retrieval of spatial and temporal context memory in healthy young versus older adults. Neuropsychologia, 48, 4020-4030.

Ranganath, C., Ritchey, M. (2012). Two cortical systems for memory-guided behaviour. Nature Review Neuroscience, 13, 713-726.

Rekkas, P. V., \& Constable, R. T. (2005). Evidence that autobiographic memory retrieval does not become independent of the hippocampus: an fMRI study contrasting very recent with remote events. Journal of Cognitive Neuroscience, 17, 1950-1961.

Rey, A. (1970). Test de m'emorisation d'une s'erie de 15 mots. In: L'examen clinique en psychologie. Paris: PUF.

Rosen, H. J., Gorno-Tempini, M. L., Goldman, W. P., Perry, R. J., Schuff, N., Weiner, M., Feiwell, R., Kramer, J.H., \& Miller, B.L. (2002). Patterns of brain atrophy in frontotemporal dementia and semantic dementia. Neurology, 58, 198-208.

Royer, S., Sirota, A., Patel, J., Buzsaki, G. (2010). Distinct representations and theta dynamics in dorsal and ventral hippocampus. Journal of Neuroscience, 30, 17771787.

Snowden, J. S., Bathgate, D., Varma, A., Blackshaw, A., Gibbons, Z. C., \& Neary, D. (2001). Distinct behavioural profiles in frontotemporal dementia and semantic dementia. The Journal of Neurology, Neurosurgery, and Psychiatry, 70, 323-332.

Snowden, J. S., Goulding, P. J., \& Neary, D. (1989). Semantic dementia: A form of circumscribed cerebral atrophy. Behavioral Neurology, 2, 167-182.

Snowden, J. S., Griffiths, H. L., \& Neary, D. (1996). Semantic-episodic memory interactions in semantic dementia: Implications for retrograde memory function. Cognitive Neuropsychology, 13, 1101-1137.

Svoboda, E., McKinnon, M. C., \& Levine, B. (2006). The functional neuroanatomy of autobiographical memory: a meta-analysis. Neuropsychologia, 44, 2189-2208.

Thompson, S.A., Patterson, K., Hodges, J.R. (2003). Left/right asymmetry of atrophy in semantic dementia: behavioral-cognitive implications. Neurology, 61, 1196-1203.

van de Pol, L. A., Hensel, A., van der Flier, W. M., Visser, P. J., Pijnenburg, Y. A., Barkhof, F., Gertz, H. J., \& Scheltens, P. (2006). Hippocampal atrophy on MRI in frontotemporal lobar degeneration and Alzheimer's disease. The Journal of Neurology, Neurosurgery, and Psychiatry, 77, 439-442. 
Viard, A., Desgranges, B., Eustache, F., \& Piolino, P. (2012). Factors affecting medial temporal lobe engagement for past and future episodic events: an ALE metaanalysis of neuroimaging studies. Brain and Cognition, 80, 111-125.

Viard, A., Chételat, G., Lebreton, K., Desgranges, B., Landeau, B., de La Sayette, V., Eustache, F., Piolino, P. (2011a). Mental time travel into the past and the future in healthy aged adults: an fMRI study. Brain and Cognition, 75, 1-9.

Viard, A., Doeller, C. F., Hartley, T., Bird, C. M., \& Burgess, N. (2011b). Anterior hippocampus and goal-directed spatial decision making. Journal of Neuroscience, 31, 4613-4621.

Viard, A., Lebreton, K., Chételat, G., Desgranges, B., Landeau, B., Young, A., De La Sayette, V., Eustache, F., \& Piolino, P. (2010). Patterns of hippocampal-neocortical interactions in the retrieval of episodic autobiographical memories across the entire life-span of aged adults. Hippocampus, 20, 153-165.

Viard, A., Piolino, P., Desgranges, B., Chételat, G., Lebreton, K., Landeau, B., Young, A., de la Sayette, V., \& Eustache F. (2007). Hippocampal activation for autobiographical memories over the entire lifetime in healthy aged subjects: An fMRI study. Cerebral Cortex, 17, 2453-2467.

Westmacott, R., Leach, L., Freedman, M., \& Moscovitch, M. (2001). Different patterns of autobiographical memory loss in semantic dementia and medial temporal lobe amnesia: A challenge to consolidation theory. Neurocase, 7, 37-55.

Wittmann, B.C., Schott, B.H., Guderian, S., Frey, J.U., Heinze, H.J., Düzel, E. (2005). Reward-related FMRI activation of dopaminergic midbrain is associated with enhanced hippocampus-dependent long-term memory formation. Neuron, 45, 459467.

Yesavage, J.A., Brink, T.L., Rose, T.L., Lum, O., Huang, V., Adey, M.B., Leir, O. (1983). Development and validation of a geriatric depression screening scale: a preliminary report. Journal of Psychiatry Research, 17, 37-49. 
Table 1 : Scores on neuropsychological tests for patients JPL and EP. Pathological scores appear in bold. HE: healthy elders.

Neuropsychological tests HE (mean \pm s.d.) JPL $\quad$ z-score $\quad$ EP $\quad$ z-score

Episodic memory

$\begin{array}{rccccc}\text { Immediate recall }(/ 16) & 15.42 \pm 0.99 & 12 & \mathbf{- 3 . 4 5 5} & 16 & 0.586 \\ \text { Free recall }(/ 48) & 31.75 \pm 5.36 & 24 & -1.446 & 31 & -0.140 \\ \text { Total recall }(/ 48) & 46.67 \pm 1.92 & 38 & -4.516 & 47 & 0.172 \\ \text { Delayed recall }(/ 16) & 11 \pm 2.22 & 9 & -0.901 & 14 & 1.351\end{array}$

Semantic memory

Category fluency (/2min)

Letter fluency (/2min)

Semantic Knowledge Task

Picture naming $(/ 36)$

$\begin{array}{ccccc}32.64+/-7.9 & 17 & -1.980 & 9 & -2.992 \\ 23.78+/-8.35 & 7 & -2.010 & 26 & 0.266\end{array}$

Categorical knowledge (/54)

$36+/-0.0 \quad 30$

Attribute knowledge (/54)

Mill Hill (/33)

Language

Picture naming (/80)

Other

MMSE (/30)

GDS (/30)

Mattis (/144)

$54+/-0.0$

30

pathological 32

pathological

$54+/-0.0$

49

$25.64 \pm 5.84$

16

pathological 50

pathological

$\begin{array}{lll}-1.651 & 29 & 0.575\end{array}$

$72.8 \pm 3.28$

55

$-5.427 \quad 60$

$-3.902$

Verbal initiation (/20)

$28.42 \pm 1.38$

$4.83 \pm 3.04$

27

$-1.029$

29

0.420

$142.17 \pm 1.34 \quad 132$

0.714

5

0.056

$(19.0 \pm 1.13) \quad 12$

$\begin{array}{ll}-7.590 & 141\end{array}$

$-0.873$

Similitude (/8)

$(8.0 \pm 0.0)$

$-6.195$

20

0.885

8

Tests: Episodic memory: Grober and Buschke (1987); MMSE : Mini-Mental Status Exam (Folstein et al., 1975); Semantic Knowledge Task : Desgranges et al. (1996);

Picture naming : LEXIS (de Partz, 2001). 
Viard et al.

Table 2 : Behavioural ratings for JPL, EP and healthy elders (HE) and z-score values comparing each patient to the control group for each period. Results were considered as significant when $z> \pm 1.96, p<0.05$. Significant results appear in bold.

HE JPL $\quad$ EP

\section{Episodic scores}

$\begin{array}{lcccccc}\text { AM score } & \text { Remote } & \text { Recent } & \text { Remote } & \text { Recent } & \text { Remote } & \text { Recent } \\ \text { Mean ( } \pm \text { s.d.) } & 3.48(0.65) & 3.71(0.35) & 1.93(0.50) & 2.50(0.71) & 3.40(0.20) & 3.50(0.14) \\ \text { z-score } & & & -2.39 & \mathbf{- 3 . 4 4} & -0.12 & -0.61\end{array}$

EM score

Mean ( \pm s.d.) $\quad 2.82(1.12) \quad 3.13(0.97) \quad 1.33(0.92) \quad 1.20(0.57) \quad 2.33(0.12) \quad 2.80(0.57)$

$\begin{array}{lllll}\text { Z-score } & -1.33 & \mathbf{- 1 . 9 8} & -0.44 & -0.33\end{array}$

\section{Emotion}

Intensity encoding

\begin{tabular}{|c|c|c|c|c|c|c|}
\hline Mean ( \pm s.d.) & 7.79 (1.55) & $6.95(1.41)$ & $6.98(0.54)$ & $9.33(0.95)$ & $8.87(0.55)$ & $9.55(0.07)$ \\
\hline z-score & & & -0.52 & 1.69 & 0.69 & \\
\hline
\end{tabular}

Valence encoding

Mean (士s.d.) $\quad 5.15(2.16) \quad 6.88(1.56) \quad 8.06(0.48) \quad 7.67(1.42) \quad 8.46(0.07) \quad 8.90(0.85)$

$\begin{array}{lllll}\text { z-score } & 1.35 & 0.51 & 1.53 & 1.30\end{array}$

Intensity recall

Mean (土s.d.) $\quad 5.35(2.15) \quad 5.71(1.48) \quad 7.09(0.74) \quad 9.36(0.90) \quad 7.83(0.04) \quad 9.45(0.07)$

z-score

0.81

2.47

1.15

2.53

Valence recall

Mean ( \pm s.d.) $\quad 5.88(1.61) \quad 6.76(1.23) \quad 8.19(0.25) \quad 7.77(1.57) \quad 8.69(0.71) \quad 7.35(0.64)$

$\begin{array}{lllll}\text { z-score } & 1.43 & 0.83 & 1.75 & 0.48\end{array}$

\section{Visual mental imagery}

Mental strategy

Mean (土s.d.) $\quad 8.99(1.23) \quad 9.02(1.40) \quad 8.04(2.59) \quad 6.80(1.89) \quad 8.63(0.12) \quad 9.35(0.92)$

z-score

$\begin{array}{llll}-0.78 & -1.58 & -0.30 & 0.23\end{array}$

Image number

Mean ( \pm s.d.)

$4.25(2.57) \quad 4.82(2.22) \quad 3.06(2.21) \quad 0.40(0.57) \quad 9.20(0.69) \quad 9.00(1.41)$

z-score

$-0.46$

$-1.99$

1.92

1.88

Image quality 
Viard et al.

\begin{tabular}{lcccccc} 
Mean $( \pm$ s.d.) & $8.58(1.90)$ & $9.29(1.02)$ & $8.59(0.62)$ & $8.70(0.57)$ & $7.74(0.33)$ & $8.75(1.06)$ \\
z-score & & & 0.01 & -0.58 & -0.44 & -0.53 \\
Perspective & & & & & \\
Mean ( \pm s.d.) & $1.36(0.68)$ & $1.43(0.62)$ & $0(0)$ & $1(0)$ & $0.78(0.03)$ & $0.70(0.42)$ \\
z-score & & & -2.00 & -0.70 & -0.84 & -1.18 \\
\hline
\end{tabular}

Consciousness

$\mathrm{R} / \mathrm{K}$

Mean (士s.d.) $\quad 8.84(1.67) \quad 9.46(0.63) \quad 9.67(0.40) \quad 9.76(0.29) \quad 8.05(1.31) \quad 8.80(1.56)$

$\begin{array}{lllll}\text { Z-score } & 0.49 & 0.49 & -0.47 & -1.04\end{array}$

Repetition

Rehearsal frequency

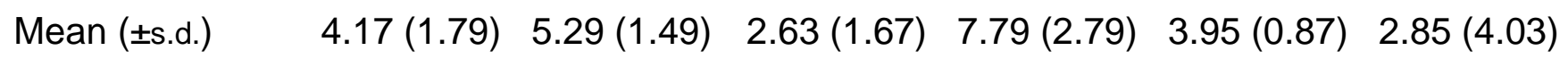

z-score $\begin{array}{llll}-0.86 & 1.68 & -0.13 & -1.63\end{array}$

\section{Last recall}

$\begin{array}{lllllll}\text { Mean }( \pm s . d .) & 6.27(2.26) & 2.43(1.37) & 8.13(1.62) & 1.01(0.74) & 7.57(1.09) & 1.15(0.92)\end{array}$

z-score

$0.83-1.04$

0.58

$-0.94$ 
Table 3 : Results for the comparisons remote $>$ control task, recent $>$ control task for JPL compared to healthy elders (HE) with age as covariate at a corrected FWE statistical threshold of $p<0.05, k>10$. BA: Brodmann area(s). L: left, R: right.

\section{Regions}

\section{Remote $>$ ctl, JPL $>\mathrm{HE}$}

Inferior frontal gyrus

Inferior frontal gyrus

Inferior temporal gyrus

Cuneus

Caudate

Remote>ctl, HE>JPL

Hippocampus

\section{Recent $>$ ctl, JPL $>$ HE}

Superior frontal gyrus

Inferior frontal gyrus

Hippocampus

Superior parietal gyrus

Superior occipital gyrus

Cuneus

Recent>ctl, HE>JPL

Calcarine sulcus

17

\section{BA Side z-score $x \quad y \quad z$}

$\begin{array}{lllllc}44 & \mathrm{~L} & 5.75 & -46 & 16 & 30 \\ 44 & \mathrm{~L} & 5.28 & -56 & 14 & 26 \\ 37 & \mathrm{~L} & 5.14 & -50 & -52 & -8 \\ 37 & \mathrm{~L} & 5.03 & -46 & -46 & -14 \\ 18 & \mathrm{~L} & 5.67 & -12 & -80 & 16 \\ & \mathrm{R} & 5.67 & 18 & 22 & 12\end{array}$

$\begin{array}{cccccc}6 & \mathrm{R} & 5.23 & 26 & -4 & 64 \\ 45 & \mathrm{~L} & 5.42 & -50 & 14 & 6 \\ & \mathrm{R} & 5.06 & 40 & -36 & -8 \\ 7 & \mathrm{~L} & 5.36 & -34 & -68 & 56 \\ 19 & \mathrm{R} & 5.62 & 20 & -78 & 22 \\ 18 & \mathrm{~L} & 5.40 & -10 & -72 & 22\end{array}$

${ }^{*} p_{\text {unc }}<0.001$
$\begin{array}{lllll}\mathrm{L} & 4.76^{*} & -30 & -12 & -18\end{array}$ 
Table 4 : Results for the comparisons remote $>$ control task, recent $>$ control task for EP compared to healthy elders $(\mathrm{HE})$ with age and education level as covariates at a corrected FWE statistical threshold of $p<0.05, k>10$. BA, Brodmann area(s). L: left, R: right.

\begin{tabular}{lcccccc} 
Regions & BA & Side & z-score & X & y & z \\
\hline Remote $>$ ctl, EP>HE & & & & & & \\
Precuneus & 7 & L & 6.12 & -6 & -42 & 66 \\
Middle occipital gyrus & 19 & R & 6.11 & 38 & -68 & 0 \\
& 19 & L & 5.73 & -44 & -82 & 10 \\
Inferior frontal gyrus & 45 & L & $4.61^{*}$ & -46 & 38 & 16 \\
Hippocampus & & L & $4.49^{*}$ & -28 & -14 & -16 \\
Hippocampus & & R & $3.34^{*}$ & 24 & -10 & -14 \\
& & & & & & \\
Recent>ctl. EP>HE & & & & & & \\
Middle occipital gyrus & 19 & L & 5.02 & -44 & -82 & 10 \\
Hippocampus & & L & $4.78^{*}$ & -32 & -18 & -12 \\
& & L & $4.21^{*}$ & -26 & -12 & -16 \\
& & $\mathrm{R}$ & $3.55^{*}$ & 20 & -12 & -14 \\
Superior temporal gyrus & 22 & $\mathrm{R}$ & $4.55^{*}$ & 68 & -32 & 6 \\
Superior parietal gyrus & 7 & $\mathrm{~L}$ & $4.45^{*}$ & -34 & -66 & 56 \\
& & & & & & \\
* ${ }_{\text {Punc }<0.001}$ & & & & & &
\end{tabular}


Viard et al.

Table 5 : Results for contrast remote vs. recent for JPL compared to healthy elders $(\mathrm{HE})$ with age as covariate at a corrected FWE statistical threshold of $p<0.05, k\rangle$ 10. BA: Brodmann area(s). L: left, R: right.

Regions

BA Side z-score $x \quad y \quad z$

Remote>Recent. JPL $>\mathrm{HE}$

$\begin{array}{lllllll}\text { Inferior frontal gyrus } & 44 & \mathrm{~L} & 5.42 & -44 & 14 & 28\end{array}$

Recent>Remote. JPL $>\mathrm{HE}$

$\begin{array}{lllllll}\text { Middle frontal gyrus } & 9 & \mathrm{~L} & 6.06 & -42 & 14 & 38\end{array}$ 
Viard et al.

Table 6 : Results for contrast remote versus recent for EP compared to healthy elders (HE) with age and education level as covariates at a corrected FWE statistical threshold of $p<0.05, k>10$. BA: Brodmann area(s). L: left, R: right.

\begin{tabular}{lcccccc} 
Regions & BA & Side & z-score & $\mathbf{x}$ & $\mathbf{y}$ & $\mathbf{z}$ \\
\hline Remote>Recent. EP>HE & & & & & & \\
Middle frontal gyrus & 9 & $\mathrm{~L}$ & 5.33 & -40 & 16 & 32 \\
Superior frontal gyrus & 6 & $\mathrm{~L}$ & 5.20 & -12 & -8 & 64 \\
Superior temporal gyrus & 22 & $\mathrm{R}$ & 5.17 & 54 & -36 & 10 \\
Inferior parietal gyrus & 40 & $\mathrm{~L}$ & 5.11 & -44 & -42 & 48 \\
Precuneus & 7 & $\mathrm{~L}$ & 5.06 & -6 & -40 & 66
\end{tabular}

Recent $>$ Remote. EP>HE

Middle frontal gyrus

Precentral gyrus

46

$\begin{array}{llllll}6 & \mathrm{~L} & 5.23 & -36 & -4 & 44\end{array}$


Table 7: Brain regions showing functional connectivity (PPI) changes with the hippocampal seed regions during recent or remote memory retrieval compared to the corresponding control condition at an uncorrected statistical threshold of $p<0.001$, $k>10)$.

\begin{tabular}{|c|c|c|c|c|c|c|}
\hline Regions & BA & Side & z-score & $\mathbf{x}$ & $\mathbf{y}$ & $\mathbf{z}$ \\
\hline \multicolumn{7}{|c|}{$\begin{array}{l}\text { Recent }>\text { ctI } \\
\text { JPL } \\
\text { PPI results for right hippocampal seed [40 }-36-8]\end{array}$} \\
\hline Middle occipital gyrus & 19 & $\mathrm{~L}$ & 3.48 & -38 & -74 & 16 \\
\hline \multicolumn{7}{|c|}{$\begin{array}{l}\text { EP } \\
\text { PPI results for left hippocampal seed [-32 }-18-10]\end{array}$} \\
\hline Hippocampus & & $\begin{array}{l}\mathrm{L} \\
\mathrm{R}\end{array}$ & $\begin{array}{l}3.79 \\
3.27\end{array}$ & $\begin{array}{l}-38 \\
16\end{array}$ & $\begin{array}{l}-38 \\
-4\end{array}$ & $\begin{array}{l}-2 \\
-14\end{array}$ \\
\hline Fusiform gyrus & 19 & $\mathrm{~L}$ & 3.18 & -28 & -66 & -10 \\
\hline Lingual gyrus & 18 & L & 3.95 & -22 & -76 & -12 \\
\hline Superior occipital gyrus & 18 & L & 3.62 & -12 & -98 & 8 \\
\hline Inferior occipital gyrus & 18 & L & 3.24 & -40 & -70 & -8 \\
\hline \multirow[t]{2}{*}{ Cerebellum } & & L & 4.85 & -32 & -80 & -26 \\
\hline & & $\mathrm{R}$ & 3.6 & 12 & -78 & -18 \\
\hline \multicolumn{7}{|c|}{ PPI results for left hippocampal seed [-26 $-12-16]$} \\
\hline \multirow[t]{3}{*}{ Hippocampus } & & $\mathrm{L}$ & 4.07 & -34 & -34 & 0 \\
\hline & & $\mathrm{R}$ & 3.63 & 16 & -4 & -12 \\
\hline & & L & $3.31^{*}$ & -32 & -12 & -18 \\
\hline
\end{tabular}

PPI results for right hippocampal seed [20 -12 -14]

No significant voxels

Remote $>$ ctl

EP

PPI results for right hippocampal seed [24 -10 -14]

\begin{tabular}{|c|c|c|c|c|c|c|}
\hline \multirow[t]{2}{*}{ Hippocampus } & & $\mathrm{R}$ & 4.28 & 34 & -24 & -14 \\
\hline & & $\mathrm{R}$ & 3.20 & 34 & -42 & 2 \\
\hline \multirow[t]{3}{*}{ Inferior frontal gyrus } & 44 & L & 5.02 & -42 & 32 & 24 \\
\hline & 44 & L & 4.75 & -52 & 28 & 26 \\
\hline & 44 & L & 3.87 & -58 & 14 & 26 \\
\hline Superior medial frontal gyrus & 9 & L & 3.63 & -12 & 34 & 30 \\
\hline \multirow[t]{3}{*}{ Middle frontal gyrus } & 11 & $\mathrm{R}$ & 4.01 & 34 & 40 & -10 \\
\hline & 9 & $\mathrm{~L}$ & 3.47 & -44 & 16 & 42 \\
\hline & 9 & $\mathrm{~L}$ & 3.39 & -48 & 14 & 34 \\
\hline Middle temporal gyrus & 21 & $\mathrm{R}$ & 4.20 & 70 & -28 & -2 \\
\hline
\end{tabular}


Viard et al.

$\begin{array}{lcccccc} & 21 & \mathrm{R} & 3.26 & 60 & -24 & -4 \\ \text { Superior temporal gyrus } & 21 & \mathrm{R} & 3.99 & 60 & -10 & -2 \\ & 22 & \mathrm{R} & 3.56 & 54 & -44 & 12 \\ & 21 & \mathrm{R} & 3.81 & 48 & -10 & -10 \\ \text { Inferior temporal gyrus } & 37 & \mathrm{R} & 3.55 & 48 & -66 & -8 \\ \text { Anterior cingulate cortex } & 32 & \mathrm{R} & 3.941 & 10 & 14 & 30 \\ & 24 & \mathrm{~L} & 3.57 & -10 & -6 & 34 \\ \text { Fusiform gyrus } & 37 & \mathrm{~L} & 3.71 & -24 & -44 & -16 \\ \text { Angular gyrus } & 39 & \mathrm{R} & 4.09 & 44 & -52 & 26 \\ \text { Cuneus } & & \mathrm{R} & 3.31 & 2 & -76 & 6\end{array}$

PPI results for left hippocampal seed [-28 -14 -16]

$\begin{array}{lllllrr}\text { Inferior frontal gyrus } & 44 & \mathrm{~L} & 3.42 & -40 & 18 & 18 \\ \text { Superior temporal gyrus } & 21 & \mathrm{R} & 3.52 & 50 & -12 & -10\end{array}$

${ }^{*} \mathrm{k}<10$ 
Viard et al.

Figure 1 : Structural brain scans of patients JPL and EP. Left panels show coronal sections through the brains of JPL and EP. Right panels show coronal sections of the MRI scan superimposed on which are the results of the VBM analysis for each patient at a corrected FWE threshold of $p<0.05$. The pronounced atrophy of cortical and medial temporal regions is apparent for JPL. See Table S2 (in Supplementary Materials) for full details of the VBM findings.
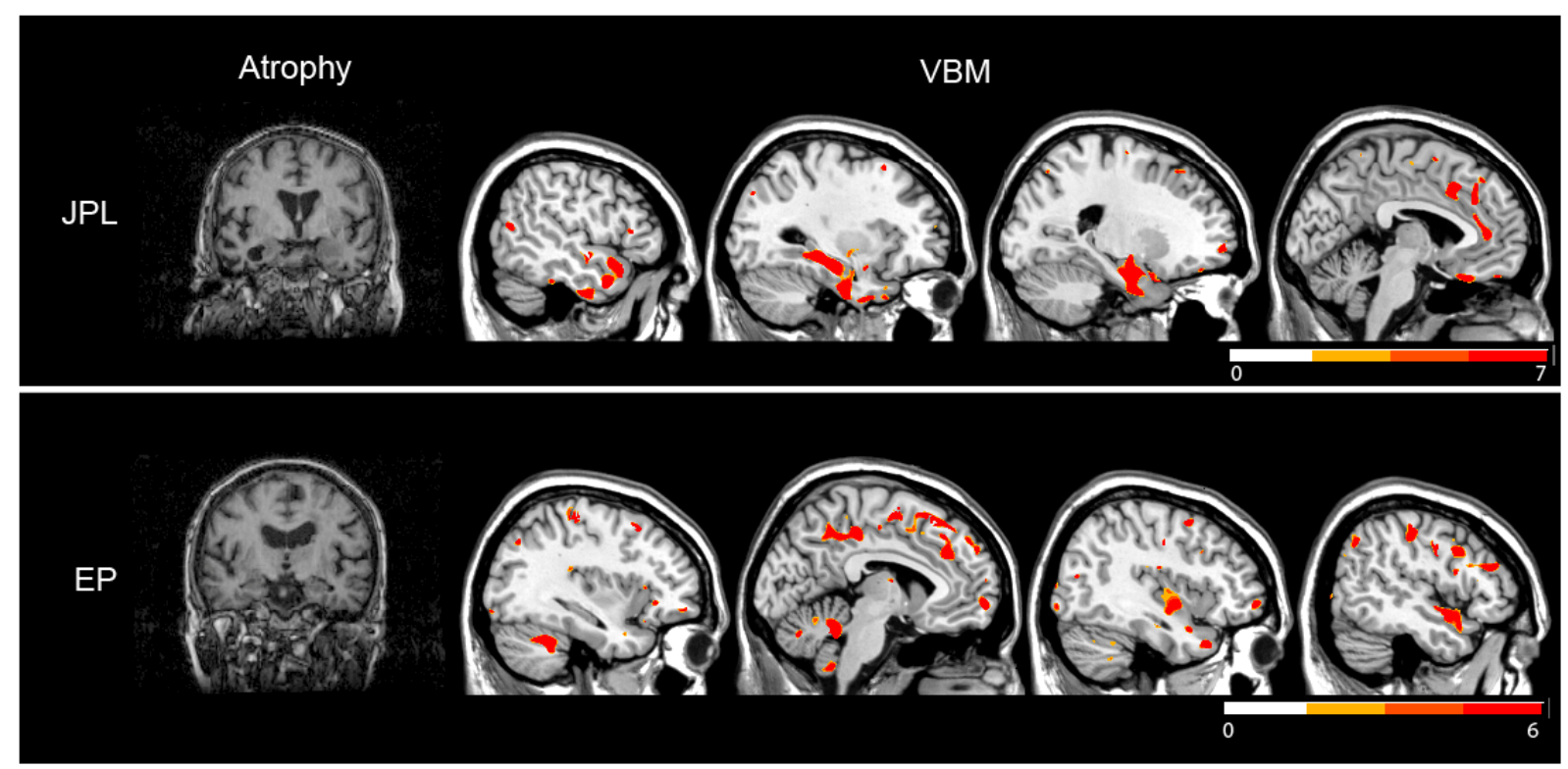
Viard et al.

Figure 2 : Results of the comparisons between remote and recent periods compared to the control task for JPL and EP compared to healthy elders (HE) at a corrected FWE threshold of $p<0.05, k>10$ voxels.

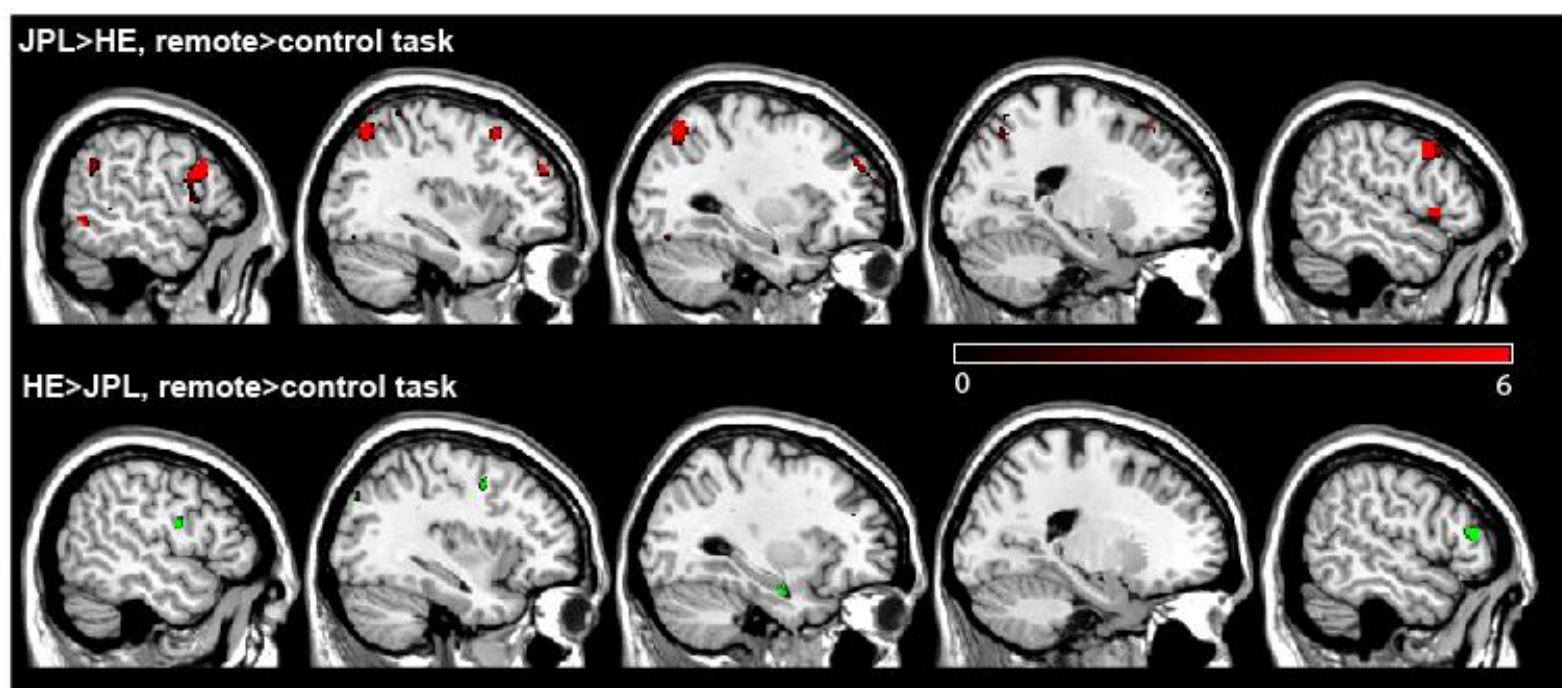

EP>HE. remote>control task

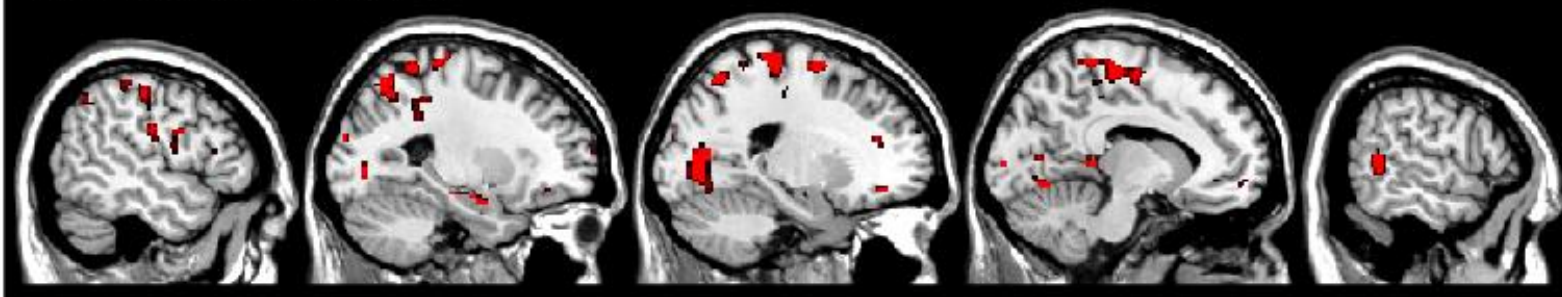

$\mathrm{EP}>\mathrm{HE}$, recent>control task

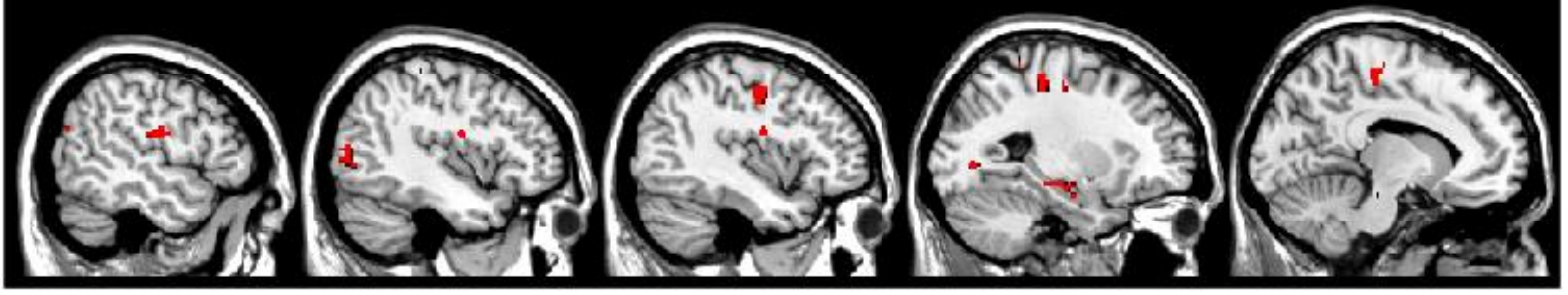


Figure 3 : Results of the comparisons between remote versus recent periods for JPL or EP compared to healthy elders $(\mathrm{HE})$ at a corrected FWE threshold of $p<0.05, k>10$ voxels.
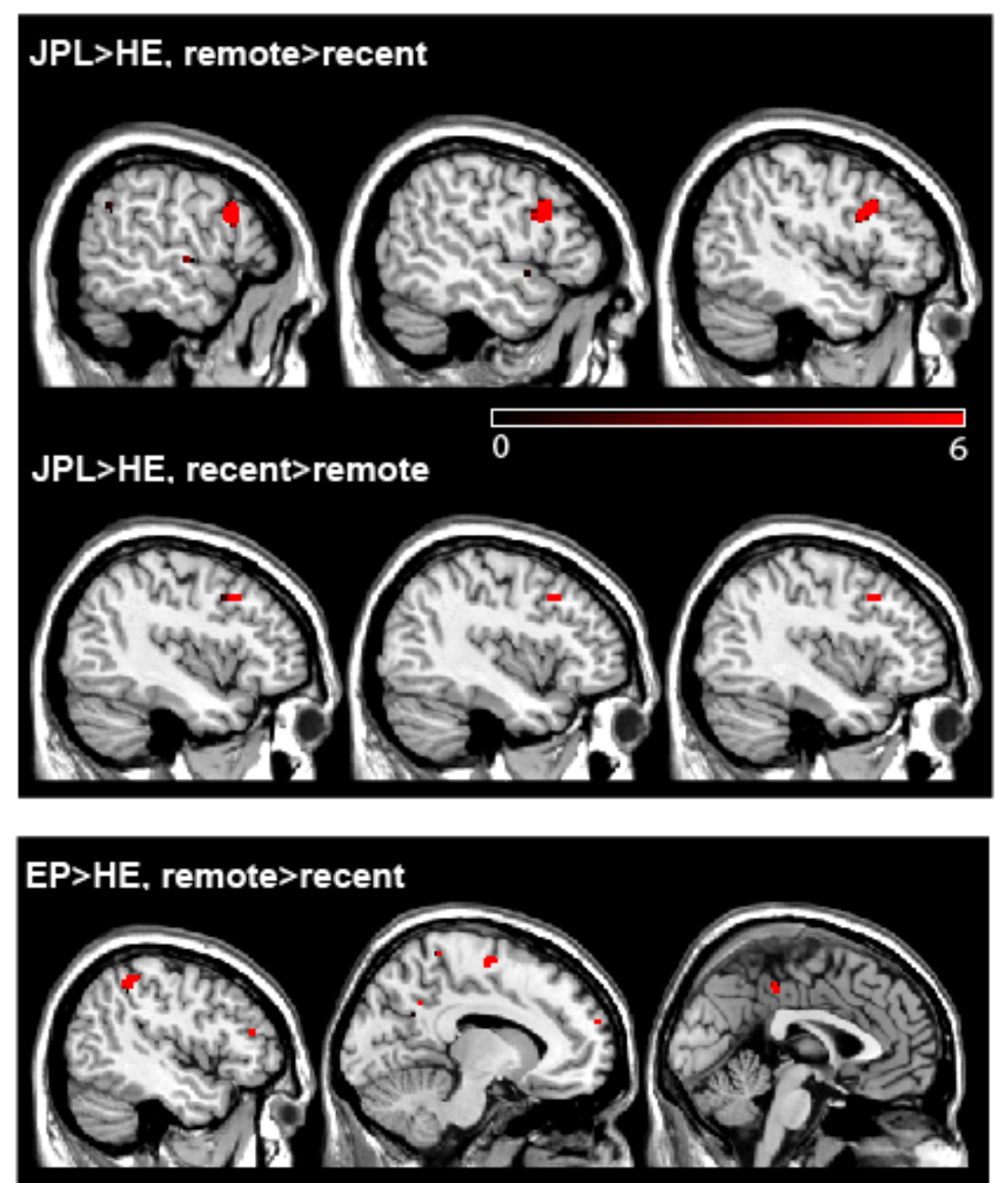

EP>HE, recent>remote

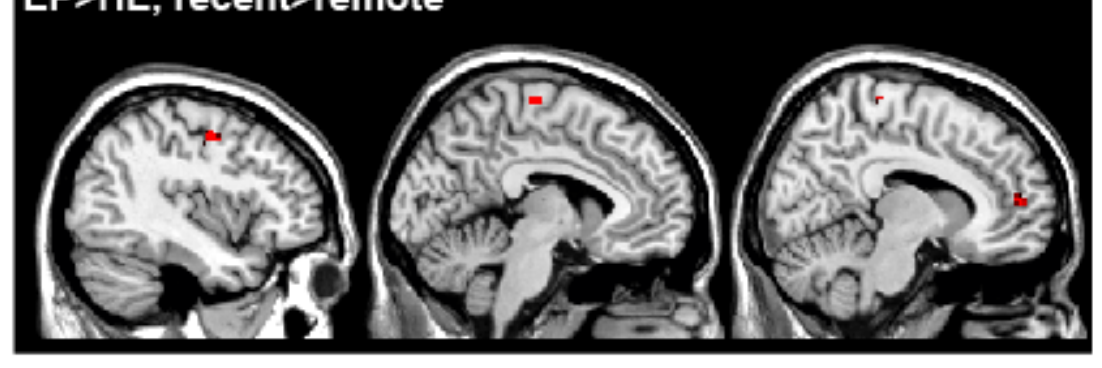


Viard et al.

Autobiographical memory in semantic dementia: new insights from two patients using fMRI

Viard et al.

\section{Supplementary Materials}

Table S1: Autobiographical scores (AS and ES) for JPL, EP and healthy elders (HE) and z-score values comparing each patient to healthy elders for each period. Results were considered as significant when $z> \pm 1.96, p<0.05$. Significant results appear in bold.

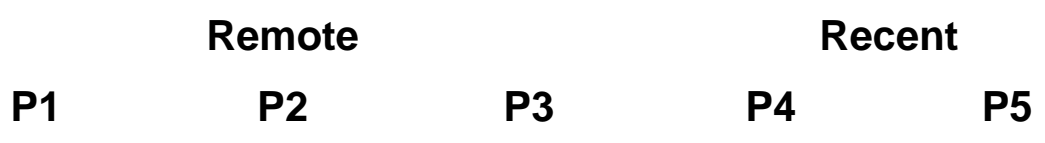

AS score

$\begin{array}{lccccc} & 3.192 & 3.679 & 3.567 & 3.696 & 3.733 \\ \mathrm{HE} & ( \pm 0.841) & ( \pm 0.334) & ( \pm 0.608) & ( \pm 0.300) & ( \pm 0.412) \\ \text { JPL } & 1.4 & 2.4 & 2 & 2 & 3 \\ \text { z-score } & -2.129 & -3.830 & -2.577 & -5.646 & -1.780 \\ \text { EP } & 3.2 & 3.6 & 3.4 & 3.4 & 3.6 \\ \text { z-score } & 0.010 & -0.237 & -0.274 & -0.985 & -0.324\end{array}$

ES score

$\begin{array}{lccccc} & 2.467 & 3.117 & 2.883 & 3.05 & 3.2 \\ \text { HE } & ( \pm 1.355) & ( \pm 0.798) & ( \pm 1.123) & ( \pm 0.891) & ( \pm 1.079) \\ \text { JPL } & 0.8 & 2.4 & 0.8 & 1.6 & 0.8 \\ \text { z-score } & -1.230 & -0.899 & -1.855 & -1.628 & \mathbf{- 2 . 2 2 5} \\ \text { EP } & 2.2 & 2.4 & 2.4 & 3.2 & 2.4 \\ \text { z-score } & -0.197 & -0.899 & -0.430 & 0.168 & -0.742\end{array}$


Viard et al.

Table S2: Areas of grey matter volume loss in JPL vs. 12 healthy elders at a corrected FWE statistical threshold of $p<0.05$. L: left, R: right.

\begin{tabular}{|c|c|c|c|c|c|}
\hline Regions & Side & z-score & $\mathbf{x}$ & $\mathbf{y}$ & $\mathbf{z}$ \\
\hline \multirow[t]{3}{*}{ Hippocampus } & $\bar{L}$ & 6.57 & -25 & -7 & -23 \\
\hline & $\mathrm{L}$ & 6.34 & -27 & -17 & -18 \\
\hline & $\mathrm{R}$ & $4.27^{*}$ & 21 & -33 & 6 \\
\hline \multirow[t]{5}{*}{ Inferior temporal gyrus } & $\mathrm{L}$ & 7.00 & -59 & -14 & -28 \\
\hline & $L$ & 6.03 & -40 & -21 & -24 \\
\hline & $\mathrm{L}$ & 6.30 & -62 & -30 & -20 \\
\hline & $\mathrm{L}$ & 5.40 & -42 & -31 & -23 \\
\hline & $\mathrm{L}$ & 5.30 & -56 & -61 & -10 \\
\hline \multirow[t]{10}{*}{ Middle temporal gyrus } & $L$ & 6.24 & -58 & -1 & -23 \\
\hline & $\mathrm{L}$ & 6.31 & -63 & -33 & 5 \\
\hline & $\mathrm{R}$ & 6.28 & 53 & 9 & -28 \\
\hline & $\mathrm{R}$ & 5.79 & 59 & -9 & -27 \\
\hline & $L$ & 5.64 & -63 & -16 & -3 \\
\hline & $\mathrm{L}$ & 5.57 & -52 & -64 & 22 \\
\hline & $L$ & 5.42 & -57 & -25 & -9 \\
\hline & $\mathrm{R}$ & 5.39 & 58 & 1 & -19 \\
\hline & $L$ & 5.34 & -63 & -47 & -8 \\
\hline & $\mathrm{L}$ & 5.31 & -45 & 40 & 21 \\
\hline \multirow[t]{3}{*}{ Middle temporal pole } & $\mathrm{L}$ & 5.84 & -30 & 2 & -41 \\
\hline & $\mathrm{R}$ & 5.45 & 39 & 17 & -36 \\
\hline & $\mathrm{L}$ & 5.35 & -29 & 18 & -32 \\
\hline Superior temporal gyrus & $L$ & 5.46 & -61 & -7 & 2 \\
\hline \multirow[t]{5}{*}{ Superior temporal pole } & $\mathrm{L}$ & 6.17 & -51 & 14 & -17 \\
\hline & $\mathrm{L}$ & 5.52 & -18 & 9 & -28 \\
\hline & $\mathrm{L}$ & 5.46 & -21 & 13 & -28 \\
\hline & $\mathrm{L}$ & 5.33 & -23 & 12 & -28 \\
\hline & $\mathrm{L}$ & 5.28 & -21 & 9 & -27 \\
\hline \multirow[t]{2}{*}{ Superior medial frontal gyrus } & $\mathrm{L}$ & 6.40 & -5 & 34 & 31 \\
\hline & $\mathrm{R}$ & 6.35 & 5 & 23 & 39 \\
\hline
\end{tabular}


Viard et al.

\begin{tabular}{|c|c|c|c|c|c|}
\hline & $\mathrm{R}$ & 6.35 & 8 & 46 & 44 \\
\hline & $L$ & 6.10 & -3 & 18 & 42 \\
\hline & $L$ & 5.28 & -7 & 56 & 34 \\
\hline \multirow[t]{4}{*}{ Superior frontal gyrus } & $\mathrm{R}$ & 6.09 & 22 & 66 & 4 \\
\hline & $L$ & 5.61 & -23 & 60 & -2 \\
\hline & $\mathrm{L}$ & 5.47 & -27 & 44 & 38 \\
\hline & $\mathrm{R}$ & 5.31 & 31 & 6 & 62 \\
\hline \multirow[t]{7}{*}{ Middle frontal gyrus } & $\mathrm{L}$ & 6.03 & -30 & 17 & 55 \\
\hline & $\mathrm{R}$ & 5.97 & 28 & 46 & 36 \\
\hline & $\mathrm{R}$ & 5.57 & 28 & 33 & 44 \\
\hline & $L$ & 5.58 & -37 & 16 & 51 \\
\hline & $\mathrm{L}$ & 5.48 & -27 & 50 & 25 \\
\hline & $\mathrm{R}$ & 5.46 & 29 & 58 & 3 \\
\hline & $L$ & 5.37 & -24 & 44 & -18 \\
\hline \multirow[t]{4}{*}{ Inferior frontal gyrus } & $\mathrm{R}$ & 5.96 & 22 & 15 & -23 \\
\hline & $L$ & 5.74 & -54 & 24 & 11 \\
\hline & $\mathrm{L}$ & 5.47 & -40 & 37 & -17 \\
\hline & $L$ & 5.31 & -38 & 20 & -9 \\
\hline \multirow[t]{2}{*}{ Superior orbitofrontal gyrus } & $\mathrm{L}$ & 5.84 & -13 & 30 & -25 \\
\hline & $\mathrm{L}$ & 5.76 & -14 & 16 & -22 \\
\hline \multirow[t]{3}{*}{ Middle orbitofrontal gyrus } & $\mathrm{L}$ & 5.82 & -26 & 35 & -11 \\
\hline & $\mathrm{R}$ & 5.33 & 27 & 55 & -14 \\
\hline & $\mathrm{R}$ & 5.31 & 35 & 54 & -11 \\
\hline \multirow[t]{3}{*}{$\mathrm{ACC}$} & $\mathrm{L}$ & 5.71 & -5 & 42 & 9 \\
\hline & $\mathrm{R}$ & 5.47 & 6 & 33 & 21 \\
\hline & $\mathrm{L}$ & 5.44 & -5 & 34 & 20 \\
\hline Insula & $\mathrm{L}$ & 6.35 & -36 & 1 & -6 \\
\hline Superior occipital gyrus & $L$ & 5.58 & -30 & -79 & 37 \\
\hline Middle occipital gyrus & $\mathrm{L}$ & 5.38 & -45 & -83 & 3 \\
\hline Supramarginal gyrus & $\mathrm{R}$ & 5.77 & 62 & -19 & 27 \\
\hline Inferior parietal gyrus & $\mathrm{L}$ & 5.51 & -57 & -52 & 53 \\
\hline Middle cingulate cortex & $\mathrm{R}$ & 5.48 & 6 & -8 & 47 \\
\hline
\end{tabular}

${ }^{*} \mathrm{p}<0.001$ uncorrected, $\mathrm{k}>500$ voxels. 
Table S3 : Areas of grey matter volume loss in EP vs. 12 healthy control participants at a corrected FWE statistical threshold of $p<0.05$. L: left, R: right.

\begin{tabular}{|c|c|c|c|c|c|}
\hline Regions & Side & z-score & $\mathbf{x}$ & $\mathbf{y}$ & $\mathbf{z}$ \\
\hline \multirow[t]{2}{*}{ Parahippocampal gyrus } & $\mathrm{L}$ & 5.40 & -18 & -11 & -24 \\
\hline & $\mathrm{R}$ & 5.28 & 30 & -20 & -19 \\
\hline Middle temporal gyrus & $\mathrm{L}$ & 5.70 & -63 & -33 & 5 \\
\hline \multirow[t]{5}{*}{ Superior temporal gyrus } & $\mathrm{R}$ & 5.34 & 52 & -5 & -7 \\
\hline & $\mathrm{R}$ & 5.53 & 51 & 2 & -13 \\
\hline & $\mathrm{R}$ & $4.56^{\star}$ & 60 & -28 & 11 \\
\hline & $\mathrm{R}$ & $4.00^{*}$ & 53 & -35 & 14 \\
\hline & $\mathrm{R}$ & $4.19^{*}$ & 47 & -21 & -3 \\
\hline Middle temporal pole & $\mathrm{R}$ & 5.30 & 39 & 19 & -34 \\
\hline \multirow[t]{4}{*}{ Superior medial frontal gyrus } & L & 6.00 & -5 & 34 & 31 \\
\hline & L & 5.78 & -9 & 39 & 51 \\
\hline & L & 5.52 & -12 & 53 & -1 \\
\hline & L & 5.51 & -6 & 62 & -5 \\
\hline \multirow[t]{4}{*}{ Middle frontal gyrus } & L & 5.94 & -30 & 17 & 55 \\
\hline & L & 5.82 & -37 & 16 & 51 \\
\hline & $\mathrm{R}$ & 5.78 & 40 & 7 & 54 \\
\hline & $\mathrm{R}$ & 5.39 & 30 & 47 & 29 \\
\hline \multirow[t]{4}{*}{ Superior frontal gyrus } & $\mathrm{L}$ & 5.89 & -13 & 23 & 58 \\
\hline & $\mathrm{R}$ & 5.86 & 12 & 42 & 48 \\
\hline & $\mathrm{R}$ & 5.64 & 23 & 67 & 4 \\
\hline & $\mathrm{L}$ & 5.57 & -17 & 41 & 48 \\
\hline \multirow[t]{2}{*}{ Inferior frontal gyrus } & $\mathrm{R}$ & 5.41 & 54 & 21 & 20 \\
\hline & $\mathrm{R}$ & 5.33 & 48 & 37 & 22 \\
\hline Middle orbitofrontal gyrus & $\mathrm{R}$ & 5.35 & 36 & 55 & -4 \\
\hline \multirow[t]{3}{*}{ SMA } & $\mathrm{R}$ & 6.43 & 15 & 0 & 66 \\
\hline & $\mathrm{R}$ & 5.80 & 7 & 4 & 52 \\
\hline & $\mathrm{L}$ & 5.39 & -6 & -2 & 60 \\
\hline \multirow[t]{2}{*}{ Precuneus } & $\mathrm{R}$ & 5.88 & 5 & -69 & 39 \\
\hline & $\mathrm{L}$ & 5.73 & -11 & -40 & 55 \\
\hline
\end{tabular}


Viard et al.

\begin{tabular}{lccccc} 
& $\mathrm{R}$ & 5.58 & 15 & -78 & 46 \\
Supramarginal gyrus & $\mathrm{L}$ & 5.33 & -8 & -52 & 47 \\
& $\mathrm{R}$ & 6.55 & 64 & -35 & 28 \\
\multirow{3}{*}{ Superior parietal gyrus } & $\mathrm{L}$ & 6.31 & -61 & -22 & 35 \\
& $\mathrm{~L}$ & 5.76 & -58 & -30 & 41 \\
& $\mathrm{~L}$ & 5.63 & -22 & -68 & 51 \\
Angular gyrus & $\mathrm{R}$ & 5.63 & 22 & -72 & 47 \\
\multirow{3}{*}{$\begin{array}{l}\text { Middle cingulate cortex } \\
\text { Cerebellum }\end{array}$} & $\mathrm{L}$ & 5.53 & -26 & -60 & 56 \\
& $\mathrm{R}$ & 5.95 & 51 & -63 & 38 \\
& $\mathrm{R}$ & 5.38 & 53 & -63 & 23 \\
& $\mathrm{~L}$ & 5.48 & -7 & -31 & 48 \\
& $\mathrm{~L}$ & 6.06 & -43 & -52 & -36 \\
& $\mathrm{~L}$ & 5.72 & -36 & -51 & -32 \\
& $\mathrm{~L}$ & 5.63 & -15 & -49 & -22 \\
& $\mathrm{~L}$ & 5.52 & -10 & -47 & -47 \\
& $\mathrm{~L}$ & 5.33 & -19 & -77 & -39 \\
& $\mathrm{R}$ & 5.33 & 8 & -61 & -15
\end{tabular}

${ }^{*} \mathrm{p}<0.001$ uncorrected, $\mathrm{k}>500$ voxels. 
Table S4 : Results of the conjunction analysis showing regions commonly active for all life periods for healthy elders (HE), JPL and EP, specifying for each peak the side ( $L$ : left, R: right). Z-scores and MNI coordinates $(x, y, z)$ at $p<0.001$ uncorrected, cluster-level $k>10$ voxels.

\begin{tabular}{lccccc} 
Regions & Side & z-score & $\mathbf{x}$ & $\mathbf{y}$ & $\mathbf{z}$ \\
\hline HE & & & & & \\
Superior frontal gyrus & $\mathrm{L}$ & 4.76 & 0 & 10 & 60 \\
Middle frontal gyrus & $\mathrm{L}$ & 4.33 & -36 & 8 & 56 \\
Hippocampus & $\mathrm{L}$ & $3.19^{*}$ & -16 & -18 & -10 \\
Parahippocampal gyrus & $\mathrm{L}$ & $3.49^{*}$ & -28 & -38 & -12 \\
Precuneus/posterior cingulate gyrus & $\mathrm{L}$ & 5.37 & -12 & -54 & 12 \\
& $\mathrm{R}$ & 4.62 & 10 & -56 & 14 \\
& $\mathrm{R}$ & 4.29 & 10 & -52 & 6 \\
Angular gyrus & $\mathrm{R}$ & 3.71 & 50 & -66 & 26 \\
Middle occipital gyrus & $\mathrm{L}$ & 4.85 & -42 & -74 & 36 \\
JPL & & & & & \\
Superior frontal gyrus & & & & & \\
Fusiform gyrus & $\mathrm{L}$ & 3.20 & -6 & 4 & 56 \\
Precuneus & $\mathrm{L}$ & 3.63 & -30 & -74 & -16 \\
& $\mathrm{R}$ & 4.05 & 4 & -72 & 34 \\
Middle temporal gyrus & $\mathrm{L}$ & 3.43 & -6 & -78 & 28 \\
Calcarine & $\mathrm{L}$ & 3.84 & -60 & -60 & -6 \\
& $\mathrm{~L}$ & 4.48 & -4 & -92 & 0 \\
& $\mathrm{~L}$ & 4.10 & -2 & -80 & -10 \\
Lingual & $\mathrm{L}$ & 3.72 & -2 & -82 & -2 \\
& $\mathrm{R}$ & 3.75 & 18 & -84 & -12 \\
& $\mathrm{~L}$ & 3.74 & -18 & -62 & -12 \\
& $\mathrm{R}$ & 3.72 & 8 & -66 & 0
\end{tabular}

\section{EP}

Inferior frontal gyrus

Middle frontal gyrus

Superior frontal gyrus

Precentral gyrus

Hippocampus

Inferior temporal gyrus

Angular gyrus

$\begin{array}{lcccc}\mathrm{L} & 3.98 & -54 & 26 & 18 \\ \mathrm{~L} & 3.81 & -38 & 14 & 54 \\ \mathrm{~L} & 3.65 & -30 & 18 & 58 \\ \mathrm{~L} & 3.64 & -32 & 32 & 46 \\ \mathrm{~L} & 3.23 & -32 & 26 & 52 \\ \mathrm{~L} & 3.75 & -20 & 2 & 62 \\ \mathrm{R} & 4.63 & 18 & -22 & 62 \\ \mathrm{~L} & 3.86 & -28 & -18 & -18 \\ \mathrm{R} & 3.70 & 50 & -50 & -20 \\ \mathrm{R} & 3.35 & 48 & -60 & -26 \\ \mathrm{R} & 4.66 & 38 & -70 & 40\end{array}$


Viard et al.

Middle occipital gyrus

Inferior occipital gyrus

Lingual gyrus

${ }^{*} k<10$
$\begin{array}{lllll}\mathrm{L} & 4.46 & -16 & -96 & 10\end{array}$

$\begin{array}{lllll}\mathrm{L} & 3.66 & -18 & -96 & 20\end{array}$

$\begin{array}{lllll}\mathrm{L} & 3.57 & -12 & 92 & 26\end{array}$

$\begin{array}{lllll}\mathrm{L} & 3.82 & -24 & -82 & -4\end{array}$

$\begin{array}{lllll}\mathrm{R} & 4.31 & 18 & -74 & -8\end{array}$

$\begin{array}{lllll}\text { R } & 3.79 & 14 & -72 & 0\end{array}$ 
Table S5 : Results of the comparison between healthy elders (HE) and EP for remote and recent periods compared to the control task with age and education level as covariates, specifying for each peak the side (L: left; R: right). Z-scores and MNI coordinates $(x, y, z)$ at a corrected FWE statistical threshold of $p<0.05, k>10$ voxels.

Regions

\section{Remote $>$ ctl, HE $>$ EP}

Anterior cingulate cortex

\section{BA Side z-score $x \quad y \quad z$}

$\begin{array}{lcccccc}\text { Recent>ctl, HE>EP } & & & & & \\ \text { Superior medial frontal gyrus } & 11 & \mathrm{R} & 6.04 & 4 & 20 & -10 \\ \text { Superior frontal gyrus } & 9 & \mathrm{~L} & 5.50 & -20 & 54 & 28 \\ \text { Middle frontal gyrus } & 10 & \mathrm{R} & 5.25 & 28 & 48 & 24 \\ \text { Hippocampus } & & \mathrm{R} & 5.79 & 38 & -28 & -10 \\ \text { Superior temporal gyrus } & 21 & \mathrm{R} & 6.05 & 56 & -8 & -8 \\ & 21 & \mathrm{R} & 5.32 & 60 & -6 & 0 \\ \text { Middle temporal pole } & 38 & \mathrm{R} & 5.98 & 48 & 8 & -20 \\ & 39 & \mathrm{R} & 5.76 & 38 & -52 & 16 \\ \text { Inferior temporal gyrus } & 20 & \mathrm{R} & 5.79 & 52 & -38 & -18 \\ \text { Fusiform cortex } & 36 & \mathrm{~L} & 5.88 & -24 & -38 & -20 \\ \text { Caudate } & & \mathrm{L} & 6.07 & -8 & 16 & -10 \\ & & \mathrm{~L} & 6.05 & -4 & 10 & -6 \\ \text { Cerebellum } & & \mathrm{R} & 5.41 & 30 & -42 & -24\end{array}$


Viard et al.

Figure S1: Quantitative volume measures of the right and left hippocampi for JPL, EP and healthy elders (HE).
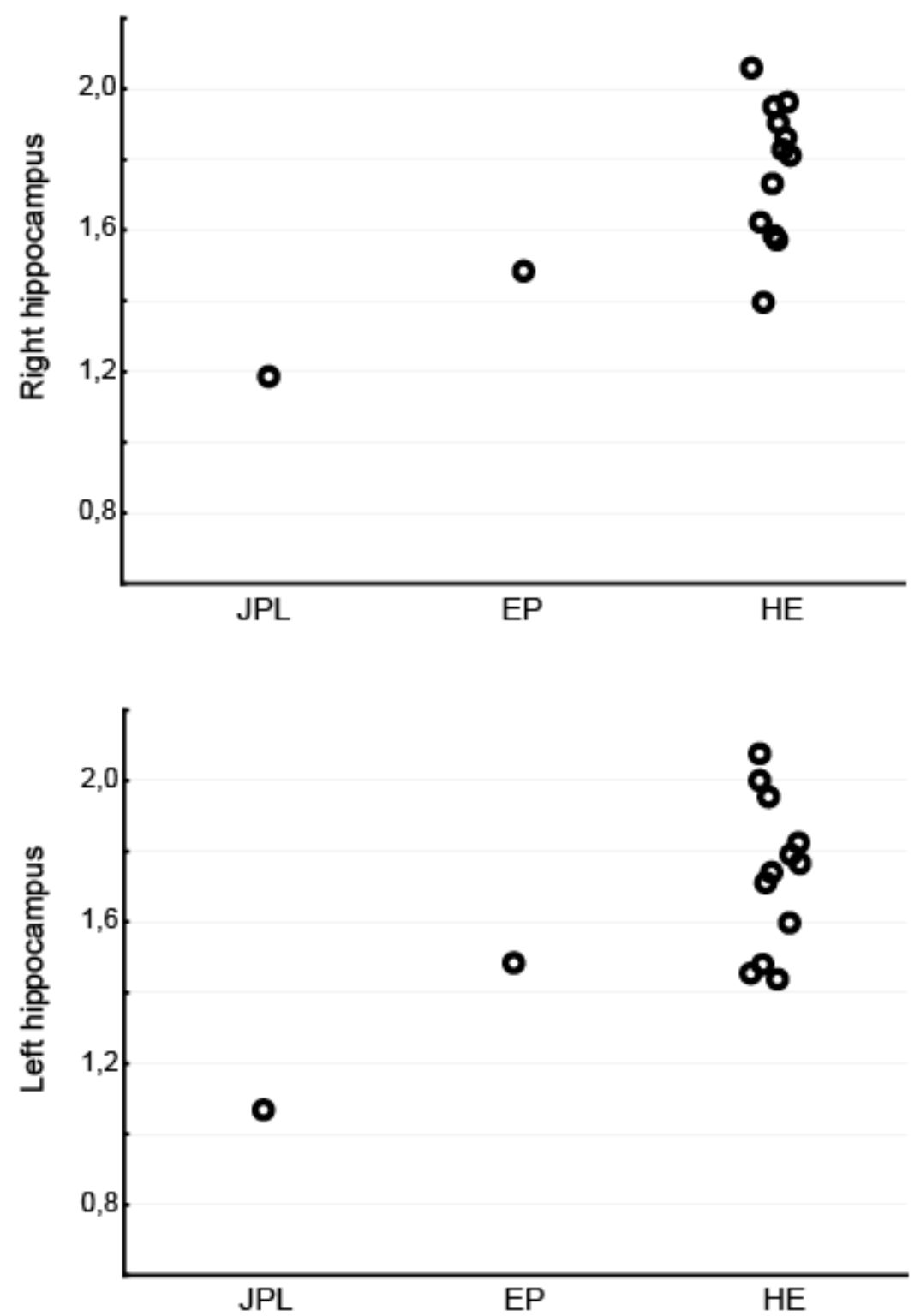